\title{
Nitrite reduction by xanthine oxidase family enzymes: a new class of nitrite reductases
}

\author{
Luisa B. Maia · José J. G. Moura
}

Received: 9 August 2010/ Accepted: 19 November 2010/Published online: 19 December 2010 (C) SBIC 2010

\begin{abstract}
Mammalian xanthine oxidase (XO) and Desulfovibrio gigas aldehyde oxidoreductase (AOR) are members of the XO family of mononuclear molybdoenzymes that catalyse the oxidative hydroxylation of a wide range of aldehydes and heterocyclic compounds. Much less known is the $\mathrm{XO}$ ability to catalyse the nitrite reduction to nitric oxide radical (NO). To assess the competence of other $\mathrm{XO}$ family enzymes to catalyse the nitrite reduction and to shed some light onto the molecular mechanism of this reaction, we characterised the anaerobic XO- and AORcatalysed nitrite reduction. The identification of $\mathrm{NO}$ as the reaction product was done with a NO-selective electrode and by electron paramagnetic resonance (EPR) spectroscopy. The steady-state kinetic characterisation corroborated the XO-catalysed nitrite reduction and demonstrated, for the first time, that the prokaryotic AOR does catalyse the nitrite reduction to NO, in the presence of any electron donor to the enzyme, substrate (aldehyde) or not (dithionite). Nitrite binding and reduction was shown by EPR spectroscopy to occur on a reduced molybdenum centre. A molecular mechanism of AOR- and XO-catalysed nitrite reduction is discussed, in which the higher oxidation states of molybdenum seem to be involved in oxygen-atom insertion, whereas the lower oxidation states would favour oxygenatom abstraction. Our results define a new catalytic performance for AOR - the nitrite reduction - and propose a new class of molybdenum-containing nitrite reductases.
\end{abstract}

L. B. Maia · J. J. G. Moura ( $\square)$

REQUIMTE, Centro de Química Fina e Biotecnologia,

Departamento de Química,

Faculdade de Ciências e Tecnologia,

Universidade Nova de Lisboa,

Campus da Caparica,

2829-516 Caparica, Portugal

e-mail: jose.moura@dq.fct.unl.pt
Keywords Nitrite reduction - Nitric oxide formation . Molybdenum $\cdot$ Xanthine oxidase $\cdot$ Aldehyde oxidoreductase

$\begin{array}{ll}\text { Abbreviations } & \\ \text { AOR } & \text { Aldehyde oxidoreductase } \\ \text { DMSOR } & \text { Dimethylsulfoxide reductase } \\ \text { EPR } & \text { Electron paramagnetic resonance } \\ \mathrm{Fe} / \mathrm{S} & \text { Iron-sulfur centre } \\ \mathrm{Fe} / \mathrm{S}-\mathrm{NO} & \text { Dinitrosyl-iron-sulfur complex } \\ (\mathrm{MGD})_{2}-\mathrm{Fe} & \text { Ferrous complex of di }(N \text {-methyl-D- } \\ & \text { glucamine dithiocarbamate }) \\ (\mathrm{MGD})_{2}-\mathrm{Fe}-\mathrm{NO} & \text { Mononitrosyl-iron complex } \\ \mathrm{Mo}-\mathrm{enzymes} & \text { Pterin-molybdenum-containing } \\ & \text { enzymes } \\ \mathrm{NaR} & \text { Nitrate reductases } \\ \mathrm{NO} & \text { Nitric oxide radical } \\ \mathrm{SO} & \text { Sulfite oxidase } \\ \text { XO } & \text { Xanthine oxidase }\end{array}$

\section{Introduction}

Molybdenum is present in a wide variety of enzymes, in both prokaryotes and eukaryotes, where it performs catalytic roles in important redox reactions of the carbon, nitrogen and sulfur cycles [1-3]. Additionally, heterometallic clusters of molybdenum are also found in other proteins whose physiological function is not yet known $[4,5]$.

With the exception of the unique iron-molybdenum cofactor of the nitrogenase, molybdenum is found in enzyme catalytic sites coordinated by the cis-dithiolene 
a<smiles></smiles>

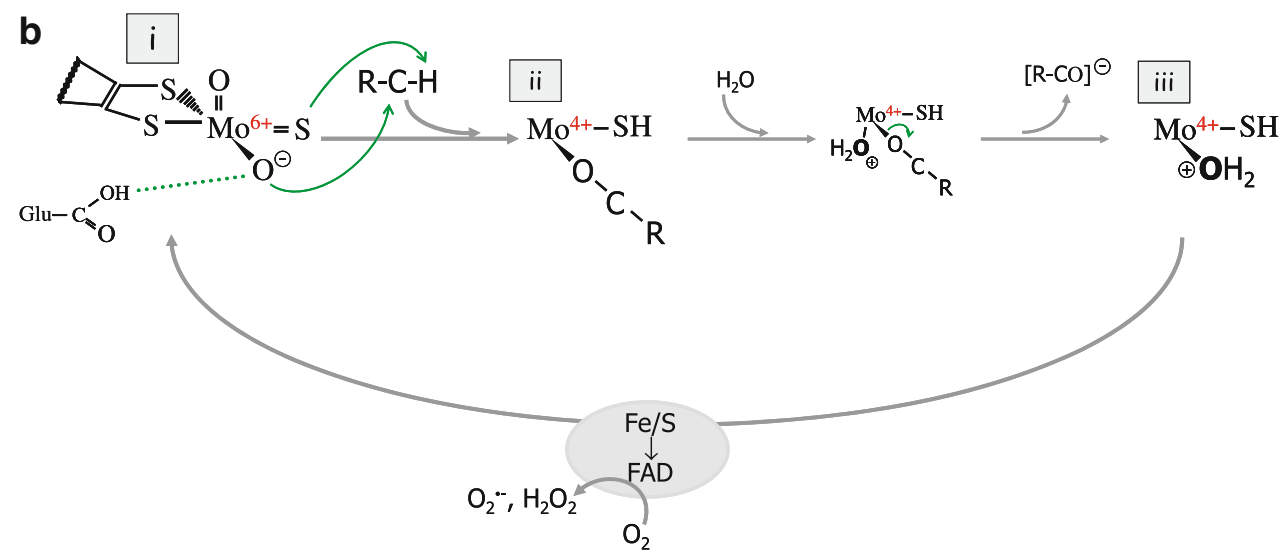

Scheme 1 The pterin cofactor structure (a) and the proposed mechanism of XO-catalysed hydroxylation (b). a The pterin cofactor is a pyranopterin-dithiolate moiety, which forms a five-membered ene-1,2-dithiolate chelate ring with the molybdenum atom. In eukaryotes, the pterin-molybdenum cofactor is found in the simplest monophosphate form ( $\mathrm{R}$ is one $\mathrm{H}$ atom). In prokaryotes, however, the cofactor is found esterificated with several nucleotides: $\mathrm{R}$ could be one cytidine monophosphate, one guanosine monophosphate or one adenosine monophosphate. b The oxidised molybdenum (i) is coordinated by one apical oxo group, two sulfur atoms of the pterin cofactor (not represented), one hydroxide/water and one sulfido

group of one or two pterin cofactor ${ }^{1}$ molecules (Scheme 1a) [1-3]. The coordination sphere of the molybdenum atom is completed with oxygen, sulfur or selenium atoms in a diversity of arrangements (see below). In addition, these pterin-molybdenum-containing enzymes (Mo-enzymes) may contain other redox centres, such as flavins, haems and iron-sulfur centres $(\mathrm{Fe} / \mathrm{S})$, which are involved in the intramolecular and intermolecular electron transfer processes.

According to the proposed structures of the molybdenum centres, the Mo-enzymes have been divided into three families [6]. The xanthine oxidase (XO) family has an $\mathrm{LMo}=\mathrm{X}\left(-\mathrm{OH} / \mathrm{OH}_{2}\right)(=\mathrm{O})$ core, where $\mathrm{L}$ stands for the

\footnotetext{
${ }^{1}$ The pterin-molybdenum cofactor is still commonly referred to as "molybdopterin", because, historically, the cofactor was first identified in molybdenum-containing enzymes. However, the same cofactor molecule is used to coordinate tungsten in some organisms that are able to utilise that element. To avoid confusion between molybdenum and tungsten-containing enzymes, the denomination "pterin-molybdenum cofactor", proposed by the Nomenclature Committee of the International Union of Biochemistry (http://www. chem.qmul.ac.uk/iubmb/etp/) was chosen.
}

group. For simplicity, the apical oxo group and the pterin sulfur atoms were omitted from the reduced molybdenum coordination sphere (ii, iii). The catalysis of hydroxylation is initiated by the activation of the molybdenum-labile $-\mathrm{OH} / \mathrm{OH}_{2}$ group by a neighbouring unprotonated glutamate residue. The $\mathrm{Mo}^{6+}-\mathrm{O}^{-}$formed $(i)$ makes a nucleophilic attack on the substrate carbon atom $(\mathrm{R}-\mathrm{CH})$, with simultaneous hydride transfer to $\mathrm{Mo}=\mathrm{S}(\mathrm{ii})$. Subsequently, the product $\left(\mathrm{R}-\mathrm{CO}^{-}\right)$is displaced by a water molecule and a new $-\mathrm{OH}_{2}$ moiety reoccupies the initial position (iii). The two electrons transferred from the substrate to the molybdenum are then rapidly transferred to the FAD site, where the reduction of molecular oxygen takes place

pterin cofactor and $\mathrm{X}$ represents terminal $=\mathrm{O},=\mathrm{S}$, or $=\mathrm{Se}$ groups $[7,8]$. This family comprises many enzymes with diverse functions, such as aldehyde oxidoreductase (AOR) from Desulfovibrio species, human XO and Eubacterium barkeri nicotinate dehydrogenase. The $\mathrm{CO}$ dehydrogenase from Oligotropha carboxidovorans, with its unique binuclear copper-molybdenum cofactor LMo-S-Cu-S-cysteine residue $\left(-\mathrm{OH} / \mathrm{OH}_{2}\right)(=\mathrm{O})$, is also included in the $\mathrm{XO}$ family. The sulfite oxidase (SO) family, with an LMo-Scysteine residue $\left(-\mathrm{OH} / \mathrm{OH}_{2}\right)(=\mathrm{O})$ core, includes wellknown enzymes such as human SO and plant assimilatory nitrate reductases $(\mathrm{NaR}$, enzymes that catalyse the first and rate-limiting step of nitrate assimilation in plants, algae and fungi), but also the prokaryotic sulfite dehydrogenases [9]. The dimethylsulfoxide reductase (DMSOR) family has an $\mathrm{L}_{2} \mathrm{MoXY}$ core, where $\mathrm{X}$ and $\mathrm{Y}$ represent terminal $=\mathrm{O}$, $-\mathrm{OH},=\mathrm{S}$, and $-\mathrm{SH}$ groups and/or oxygen, sulfur or selenium atoms from cysteine, selenocysteine, serine or aspartate residue side chains [10]. This is a larger and more diverse family, constituted by only prokaryotic enzymes such as the DMSOR and formate dehydrogenase, as well as dissimilatory $\mathrm{NaR}$ (periplasmic or membrane-associated 
enzymes that function as respiratory oxidases) and assimilatory NaR (cytoplasmatic enzymes), arsenite oxidase and arsenate reductase. A fourth family was recently proposed to include the pterin-tungsten cofactor-containing aldehyde:ferredoxin oxidoreductases (EC 1.2.7.5), found only in archaea [11].

In general, the Mo-enzymes catalyse the transfer of an oxygen atom from water to the product or from the substrate to water, in reactions that imply a net exchange of two electrons and in which the molybdenum cycles between $\mathrm{Mo}^{6+}$ and $\mathrm{Mo}^{4+}[1-3]$. It is based on this catalytic feature that these Mo-enzymes are frequently referred to as oxotransferases (although there is at least one important exception, the formate oxidation catalysed by the formate dehydrogenase, Eq. 1). In particular, the enzymes of the XO family catalyse the hydrolysis of a $\mathrm{C}-\mathrm{H}$ bond with formation of a $\mathrm{C}-\mathrm{O}$ bond, in reactions of oxidative hydroxylation (e.g. xanthine hydroxylation catalysed by XO, Eq. 2) [7, 8]. The hydroxybenzoyl-CoA reductase is an important exception within the XO family, as it catalyses the irreversible dehydroxylation (a reduction) of the phenol ring. The $\mathrm{CO}$ dehydrogenase is another exception, since the $\mathrm{CO}_{2}$ formation from $\mathrm{CO}$ does not involve the hydrolysis of a $\mathrm{C}-\mathrm{H}$ bond. The members of the SO family, in contrast, catalyse the simple transfer of an oxygen atom from or to a lone electron pair of the substrate (e.g. nitrate reduction catalysed by $\mathrm{NaR}$, Eq. 3, or sulfite oxidation catalysed by SO, Eq. 4, respectively) [9]. The DMSOR enzymes catalyse both the cleavage of $\mathrm{C}-\mathrm{H}$ bonds (e.g. formate oxidation, Eq. 1) and the transfer of oxygen atoms (e.g. nitrate reduction, Eq. 3) [10].

Formate oxidation (formate dehydrogenase oxidative half-reaction):

$\mathrm{HCOOH} \rightarrow \mathrm{CO}_{2}+2 \mathrm{H}^{+}+2 e^{-}$

Xanthine hydroxylation ${ }^{2}$ (XO oxidative half-reaction):

$\mathrm{R}-\mathrm{C}-\mathrm{H}+\mathrm{H}_{2} \mathrm{O} \rightarrow \mathrm{R}-\mathrm{C}-\mathrm{OH}+2 \mathrm{H}^{+}+2 e^{-}$

Nitrate reduction (NaR reductive half-reaction):

$\mathrm{NO}_{2} \mathbf{O}^{-}+2 \mathrm{H}^{+}+2 e^{-} \rightarrow \mathrm{NO}_{2}^{-}+\mathrm{H}_{2} \mathbf{O}$

Sulfite oxidation (SO oxidative half-reaction):

$\mathrm{SO}_{3}^{2-}+\mathrm{H}_{2} \mathbf{O} \rightarrow \mathrm{SO}_{3} \mathbf{O}^{2-}+2 \mathrm{H}^{+}+2 e^{-}$

Mammalian XO (EC 1.17.3.2), the prototype of the XO family, is a complex homodimer, with two different $[2 \mathrm{Fe}-$ $2 \mathrm{~S}$ ] centres (named $\mathrm{Fe} / \mathrm{S} \mathrm{I}$ and $\mathrm{Fe} / \mathrm{S}$ II) and one FAD, besides the pterin-molybdenum cofactor [7, 8, 12]. The molybdenum atom is present in a distorted square pyramidal geometry, with one apical $=\mathrm{O}$ group and with the four equatorial positions occupied by two sulfur atoms

\footnotetext{
${ }^{2}$ Xanthine and uric acid represented in neutral form.
}

of the cis-dithiolene $(-\mathrm{S}-\mathrm{C}=\mathrm{C}-\mathrm{S}-)$ group of the pterin cofactor molecule, one essential $=\mathrm{S}$ group and one labile $\mathrm{OH} /-\mathrm{OH}_{2}$ group [13]. Physiologically, XO is a key enzyme in purine catabolism, where it catalyses the hydroxylation of both hypoxanthine and xanthine to the terminal metabolite urate. However, it also catalyses the hydroxylation of a wide variety of other nitrogencontaining heterocyclic compounds and aldehydes, with the simultaneous reduction of $\mathrm{O}_{2}$ [14].

The hydroxylation catalysis $[15,16]$ is initiated with the activation of the molybdenum-labile $-\mathrm{OH} / \mathrm{OH}_{2}$ group by a neighbouring unprotonated glutamate residue (Glu-1261 in the bovine enzyme) to form $\mathrm{Mo}^{6+}-\mathrm{O}^{-}$(base-assisted catalysis) (Scheme 1b, i). The hydride transfer to the essential $=\mathrm{S}$ group follows, with the simultaneous nucleophilic attack of the $\mathrm{Mo}-\mathrm{O}^{-}$on the carbocation formed. This concerted attack results in the formation of a covalent intermediate, $\mathrm{Mo}^{4+}-\mathrm{O}-\mathrm{C}-\mathrm{R}$ (-SH) (Scheme 1b, ii). Subsequently, the product (e.g. urate) is displaced by a water molecule (Scheme 1b, ii $\rightarrow$ iii) and a new $-\mathrm{OH}_{2}$ moiety reoccupies the initial position to give $\mathrm{Mo}^{4+}-\mathrm{OH}_{2}(-\mathrm{SH})$ (Scheme 1b, iii). The two electrons thus transferred from the substrate to the molybdenum $\left(\mathrm{Mo}^{6+} \rightarrow \mathrm{Mo}^{4+}\right.$, reductive half-reaction) are then rapidly distributed throughout the Fe/S and FAD Scheme 1b, iii $\rightarrow$ i), according to their redox potentials. At the FAD site, the electrons are finally transferred to $\mathrm{O}_{2}$ (oxidative half-reaction), to give $\mathrm{O}_{2}^{\bullet-}$ and $\mathrm{H}_{2} \mathrm{O}_{2}$. The hydroxylations catalysed by the Mo-enzymes are, therefore, quite different from those of the monooxygenases, as they generate (rather than consume) reducing equivalents and use $\mathrm{O}_{2}$ as an oxidant and not as a source of oxygen atoms (which in the Mo-enzymes case is water).

In addition to $\mathrm{O}_{2}$, XO can also catalyse the reduction of several other compounds, including several sulfo- and nitro compounds. In particular, the XO ability to catalyse the nitrate reduction has long been known [17-19], but only over the last years did this activity begin to be restudied $[20,21]$. The subsequent XO-catalysed reduction of nitrite to nitric oxide radical (NO) has also been reported over the last decade [20, 22-28], but it is not yet generally recognised. Interestingly, the mammalian aldehyde oxidase [29], another member of the $\mathrm{XO}$ family, was also recently shown to catalyse the nitrite reduction to NO $[28,30]$. This XOcatalysed and aldehyde oxidase catalysed nitrite reduction assumes particular importance owing to the amount of experimental evidence that points towards the participation of these two enzymes in the human in vivo formation of NO from nitrite (as was extensively and recently reviewed in [31-35]). However, in spite of these reactions being known for a while, the molecular mechanism of nitrate and nitrite reduction remains to be elucidated.

The main goal of this article is to study the molecular mechanism of XO-catalysed nitrite reduction, to contribute 
to a better characterisation of this pathway of NO production in humans. We also intended to assess the competence of other XO family enzymes to catalyse this reduction, to enlarge the sampling and variety of kinetic and mechanistic data obtained. For this purpose, the AOR (EC 1.2.99.7) from the sulfate-reducing bacterium Desulfovibrio gigas was the family member chosen. This enzyme possesses the same overall protein architecture, with two [2Fe-2S] centres similar to the $\mathrm{XO}$ ones, although it has no FAD [36]. AOR has the molybdenum atom in the same square-pyramidal geometry as $\mathrm{XO}$, but its pterin cofactor is found esterificated with a cytidine monophosphate (pterin and cytosine dinucleotide) and it seems to have an $=\mathrm{O}$ group instead of the essential $=\mathrm{S}$ group of $\mathrm{XO}$ [37]. This enzyme catalyses the conversion of aldehydes to the respective carboxylates at the molybdenum site, and the $\mathrm{Fe} / \mathrm{S}$ are involved in the intramolecular electron transfer to an unknown physiological oxidising substrate, probably the flavodoxin [38].

To accomplish those objectives, we kinetically characterised the anaerobic XO- and AOR-catalysed nitrite reduction. The identification of $\mathrm{NO}$ as the final reaction product was done with an NO-selective electrode and by electron paramagnetic resonance (EPR) spectroscopy. The participation of the $\mathrm{XO}$ and AOR redox centres in nitrite reduction was assessed by EPR spectroscopy, in the presence of typical reducing substrates (aldehydes, xanthine and NADH), dithionite and site-specific inhibitors (allopurinol and ethylene glycol) and with samples of desulfo$\mathrm{XO}$ (an enzymatic form in which the essential $\mathrm{Mo}=\mathrm{S}$ was replaced by a $\mathrm{Mo}=\mathrm{O}$ group). The kinetic and spectroscopic results were integrated with the available structural and mechanistic data $[7,12,15,16]$ to suggest a molecular mechanism of molybdenum-dependent nitrite reduction.

\section{Materials and methods}

\section{Materials}

All the reagents were of the highest quality available and were used as supplied. XO from bovine milk, xanthine, $\mathrm{NADH}$, benzaldehyde, 2,3-dihydroxybenzaldehyde, allopurinol, sodium nitrite, sodium dithionite, $N$-methyl-Dglucamine dithiocarbamate, haemoglobin, 2,6-dichloroindophenol (sodium salt) and uric acid (sodium salt), were obtained from Sigma (Spain). All the other reagents were from Merck (Darmstadt, Germany).

\section{Enzyme samples}

D. gigas AOR was purified as previously described [39] and its concentration was determined spectrophotometrically using an $\varepsilon$ of $24,600 \mathrm{M}^{-1} \mathrm{~cm}^{-1}$ at $462 \mathrm{~nm}$ for the oxidised (as-prepared) enzyme. The XO from bovine milk was equilibrated in $50 \mathrm{mM}$ phosphate buffer, $\mathrm{pH} 7.8$, by gel filtration on a small Sephadex G-25 column (GE Healthcare Bio-Sciences, Sweden), prior the assays. Desulfo-XO was prepared by incubation with $10 \mathrm{mM} \mathrm{KCN}$, in $50 \mathrm{mM}$ phosphate buffer, $\mathrm{pH} 7.8$, for $30 \mathrm{~min}$. After gel filtration on a small Sephadex G-25 column, the desulfo-XO thus prepared showed no xanthine: $\mathrm{O}_{2}$ oxidoreductase activity.

$\mathrm{XO}$ activity (xanthine: $\mathrm{O}_{2}$ oxidoreductase activity) was measured in the presence of $20.0 \mu \mathrm{M}$ xanthine, following the formation of urate at $295 \mathrm{~nm}\left(\Delta \varepsilon=9,500 \mathrm{M}^{-1} \mathrm{~cm}^{-1}\right)$, in air-equilibrated $50 \mathrm{mM}$ phosphate buffer, $\mathrm{pH}$ 7.8. The $\mathrm{XO}$ concentration was corrected for the presence of inactive molecules assuming that $100 \%$ functional XO would have an activity-to-flavin ratio of 200 [40]. The samples used had an average activity-to-flavin ratio of 145. AOR activity was assayed in the presence of $100 \mu \mathrm{M}$ benzaldehyde, measuring the reduction of $75.0 \mu \mathrm{M}$ 2,6-dichloroindophenol, at $600 \mathrm{~nm} \quad\left(\varepsilon=21,000 \mathrm{M}^{-1} \mathrm{~cm}^{-1}\right)$ in $50 \mathrm{mM}$ phosphate buffer, $\mathrm{pH} 7.8$. The activity assays were recorded using a PC-linked UV/vis spectrophotometer (Shimadzu UV-2101PC) in a temperature-controlled and stirred cell. One unit of catalytic activity was defined as the amount of enzyme required to catalyse the oxidation of $1 \mu \mathrm{mol}$ of substrate per minute under our experimental conditions.

\section{NO measurements by spin-trapping}

The reaction mixtures were prepared in an anaerobic chamber (MBraun UniLab) and all the solutions were first deoxygenated (argon-purged). The ferrous complex of $N$-methyl-D-glucamine dithiocarbamate (MGD) $)_{2}-\mathrm{Fe}$ was prepared by mixing ferrous ammonium sulfate and $\mathrm{N}$-methyl-D-glucamine dithiocarbamate to final concentrations of 12.0 and $60.0 \mathrm{mM}$, respectively. The assays were conducted at $293 \mathrm{~K}$, in $50 \mathrm{mM}$ phosphate buffer, $\mathrm{pH} 7.4$, containing $10.0-2.00 \mathrm{mM}$ (MGD) $)_{2}-\mathrm{Fe}$ with the other reactants concentrations as indicated in the figure legends. Benzaldehyde and 2,3-dihydroxybenzaldehyde were the aldehydes used with AOR and XO, respectively. The reaction mixtures were then transferred to a quartz flat cell, the cell was sealed and the EPR spectra at $293 \mathrm{~K}$ were acquired as described below.

NO electrochemical measurements

Electrochemical measurements of NO were carried out with an NO-selective Clark-type electrode (ISO-NO ${ }^{\mathrm{TM}}$ Mark II, World Precision Instruments). The electrode was calibrated daily with known concentrations of NO, generated with acidified nitrite solutions in the presence of 
potassium iodide, as described by the electrode manufacturer. The assays were carried out in $50 \mathrm{mM}$ phosphate buffer, $\mathrm{pH}$ 7.4, with the other reactant concentrations as indicated in the figure legends, in a $1-\mathrm{cm}^{3}$ anaerobic cell and all the solutions were deoxygenated (argon-purged) for $20 \mathrm{~min}$. Benzaldehyde and 2,3-dihydroxybenzaldehyde were the aldehydes used with AOR and XO, respectively. The reactions were initiated by adding the enzyme. The steady-state apparent kinetic parameters were estimated by the direct linear method of Eisenthal and Cornish-Bowden [41] from the initial rates determined in at least three independent experiments, varying the nitrite (1-200 mM) and aldehyde $(2.50-500 \mu \mathrm{M})$ concentrations.

Molecular mechanism of nitrite reduction probed by EPR

The enzyme samples $(150 \mu \mathrm{M})$ were incubated anaerobically, at $293 \mathrm{~K}$, with the reagent (substrate, dithionite, NO and inhibitor) at the concentration and for the time mentioned before being frozen. The spectra at 20 and $100 \mathrm{~K}$ were then acquired as described in "EPR assays". The pure NO solution $(100 \mu \mathrm{M})$ was prepared by bubbling, for $30 \mathrm{~min}, 5 \% \mathrm{NO}$ gas in $50 \mathrm{mM}$ phosphate buffer, $\mathrm{pH} 7.4$ (through a $10 \% \mathrm{KOH}$ solution to remove other nitrogen oxides from the $\mathrm{NO}$ gas). The NO concentration was calculated assuming a concentration of $1.9 \mathrm{mM}$ for $100 \% \mathrm{NO}$ gas, at $293 \mathrm{~K}$.

\section{EPR assays}

X-band $(9.65 \mathrm{GHz})$ EPR spectra were recorded using a Bruker EMX 6/1 spectrometer. For $293 \mathrm{~K}$ spectra, an ER 4102ST cavity (Bruker) was used and the acquisition conditions were a modulation frequency of $100 \mathrm{kHz}$, modulation amplitude of $0.1 \mathrm{mT}$ and microwave power of $20 \mathrm{~mW}$. For low-temperature (20 and $100 \mathrm{~K})$ spectra, an ER4116DM rectangular cavity (Bruker) was used and the samples were cooled with an Oxford Instruments ESR900 continuous-flow cryostat (with liquid helium), fitted with a temperature controller. The acquisition conditions were a modulation frequency of $100 \mathrm{kHz}$, modulation amplitude of $0.5 \mathrm{mT}$ and microwave power of $633 \mu \mathrm{W}$; the spectra were acquired by sweeping the magnetic field between 325 and $375 \mathrm{mT}$, for the $20 \mathrm{~K}$ spectra, and between 335 and $360 \mathrm{mT}$, for the $100 \mathrm{~K}$ spectra.

\section{Results}

NO formation during XO-catalysed nitrite reduction

The identification of NO as the reaction product of nitrite reduction was done with an NO-selective electrode and by
EPR spectroscopy. The first approach utilises a Clark-type electrode (ISO-NO ${ }^{\mathrm{TM}}$, World Precision Instruments) that is selective for $\mathrm{NO}$ and the second one makes use of the spintrap $(\mathrm{MGD})_{2}-\mathrm{Fe}$. In the presence of $(\mathrm{MGD})_{2}-\mathrm{Fe}$, NO gives rise to a mononitrosyl-iron complex (MGD) ${ }_{2}-\mathrm{Fe}-\mathrm{NO}$ which exhibits a characteristic EPR triplet signal at $g$ of 2.04 with a hyperfine splitting of $1.27 \mathrm{mT}$ [42].

An aldehyde (dihydroxybenzaldehyde) was the first reducing substrate chosen to study the NO formation, because it would allow a direct comparison between $\mathrm{XO}$ and AOR. As shown by both methods (Figs. 1, 2, left panels), XO-catalysed nitrite reduction to $\mathrm{NO}$ is dependent on enzyme, aldehyde and nitrite concentrations and on time. Moreover, the NO formation is absolutely dependent on the simultaneous presence of enzyme, nitrite and aldehyde, as no NO formation was observed in the absence of any of those three reactants (Figs. 1, spectrum c; 2, curves $\mathrm{g}-\mathrm{i})$. This NO generation was rapidly abolished upon addition of haemoglobin (Fig. 2, curve f). Haemoglobin is an effective scavenger of NO and this NO decay confirmed that the observed curves do indeed reflect the NO formation. On the other hand, the fact that the NO formation was also triggered by xanthine (which reacts at the molybdenum centre) and NADH (which reacts at the flavin) (Fig. 2, curves $b, c)$, demonstrated that the NO formation is independent of the nature of reducing substrate and of the reduction site. It is also worth mentioning that dithionite can also promote the enzyme-dependent NO formation. Accordingly, $\mathrm{XO}$ catalyses the nitrite reduction to $\mathrm{NO}$ in the presence of any electron donor, substrate or not, reacting at any of the enzyme redox centres. The results obtained agree quite well with previously reported ones [23].

NO formation during nitrite reduction catalysed by AOR

To evaluate the ability of other XO family enzymes to catalyse the nitrite reduction, the AOR-catalysed NO formation was measured by spin-trapping and with the NOselective electrode, with benzaldehyde as the reducing substrate. AOR was found to catalyse the nitrite reduction with NO formation in an enzyme-, aldehyde- and nitriteconcentration-dependent manner. In the absence of AOR, aldehyde or nitrite (Figs. 1, 2, right panels), no significant NO formation was observed. In the presence of nitrite and aldehyde, only after the addition of AOR was the NO formation initiated (Figs. 1, spectra d, e; 2, curves j-1). Again, dithionite can also promote the AOR-dependent NO formation. However, the magnitude and the rate of NO formation catalysed by AOR were lower than those observed with XO. Taken together, these results showed that AOR, in the presence of an electron donor (substrate or not), does in fact catalyse the NO formation. 


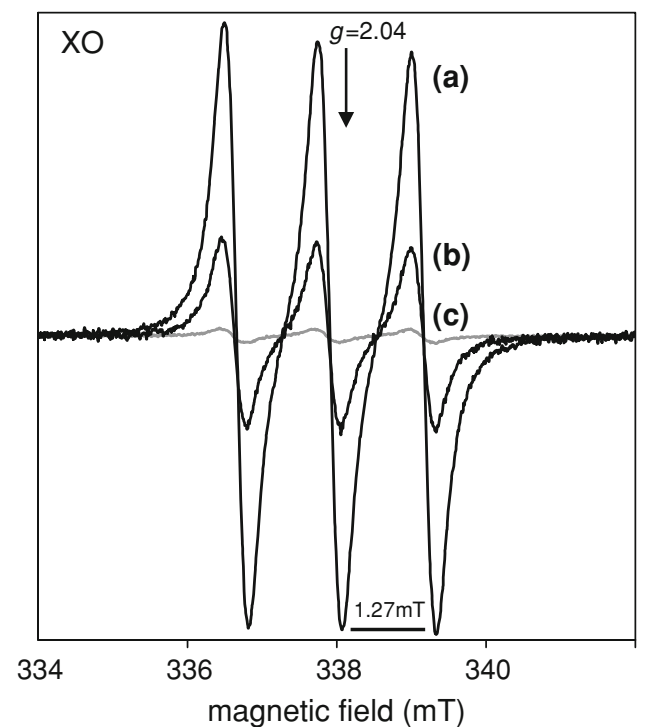

Fig. 1 XO- and AOR-catalysed NO formation evaluated by EPR spectroscopy with the spin-trap (MGD) $)_{2}-\mathrm{Fe}$. XO (left panel) or AOR (right panel) was anaerobically incubated with aldehyde and nitrite, in

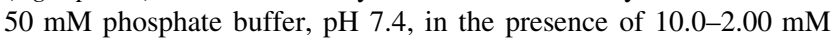
$(\mathrm{MGD})_{2}-\mathrm{Fe}$, for $30 \mathrm{~min}$, and the spectra of the (MGD) $)_{2}-\mathrm{Fe}-\mathrm{NO}$ complex formed were acquired as described in "EPR assays". The

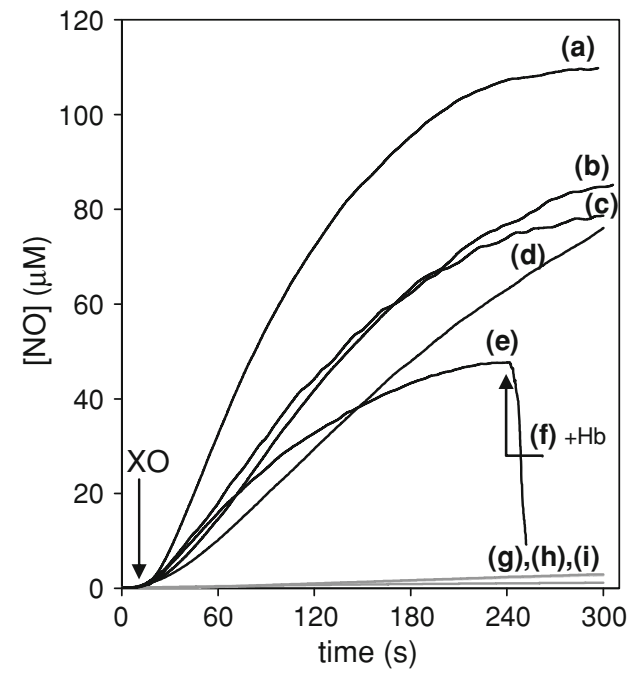

Fig. 2 Time courses of XO- and AOR-catalysed NO formation evaluated with the NO-selective electrode. Left: The anaerobic XOcatalysed NO formation during nitrite reduction by aldehyde was assayed in the presence of $2.5 \mathrm{mM}(e)$ and $25 \mathrm{mM}(a, d)$ nitrite and $50 \mu \mathrm{M}(e)$ and $100 \mu \mathrm{M}(a, d)$ dihydroxybenzaldehyde, with $0.33 \mu \mathrm{M}$ (d) or $1.00 \mu \mathrm{M}(a, e) \mathrm{XO}$. To demonstrate the nitrite reduction in the presence of other reducing substrates, NO formation was followed in the presence of $25 \mathrm{mM}$ nitrite and $1 \mathrm{mM}$ NADH $(b)$ or $50 \mu \mathrm{M}$ xanthine $(c)$, with $75.0 \mathrm{nM}(c)$ and $1.00 \mu \mathrm{M}(b)$ XO. The effect on NO formation of adding haemoglobin $(+H b)$ is illustrated in curve $e$. Haemoglobin $(100 \mu \mathrm{M})$ was added at the point indicated by the

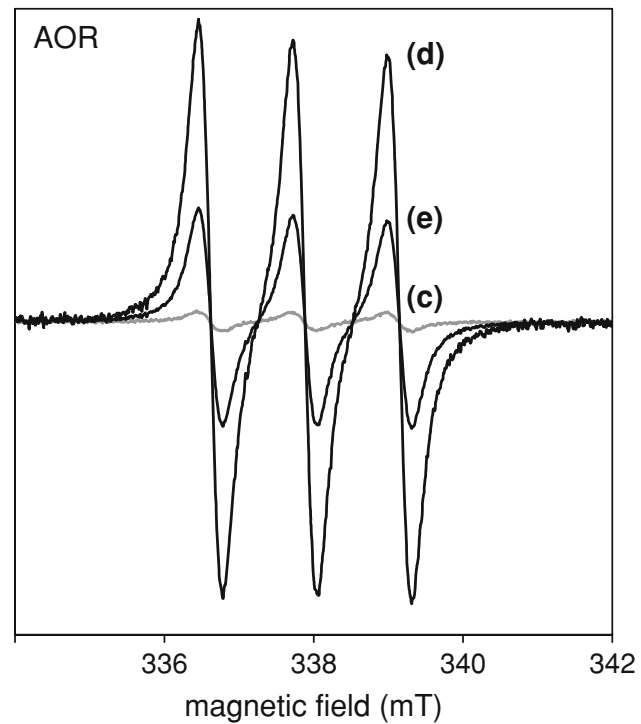

reaction mixtures contained $117 \mathrm{nM}(b)$ or $350 \mathrm{nM}(a)$ XO with $400 \mu \mathrm{M}$ dihydroxybenzaldehyde and $2.00 \mathrm{mM}$ nitrite and $1.40 \mu \mathrm{M}$ (e) or $2.50 \mu \mathrm{M}(d)$ AOR with $1.40 \mathrm{mM}$ benzaldehyde and $1.70 \mathrm{mM}$ nitrite. The spectrum of a control assay $(c)$, without enzyme, is also shown

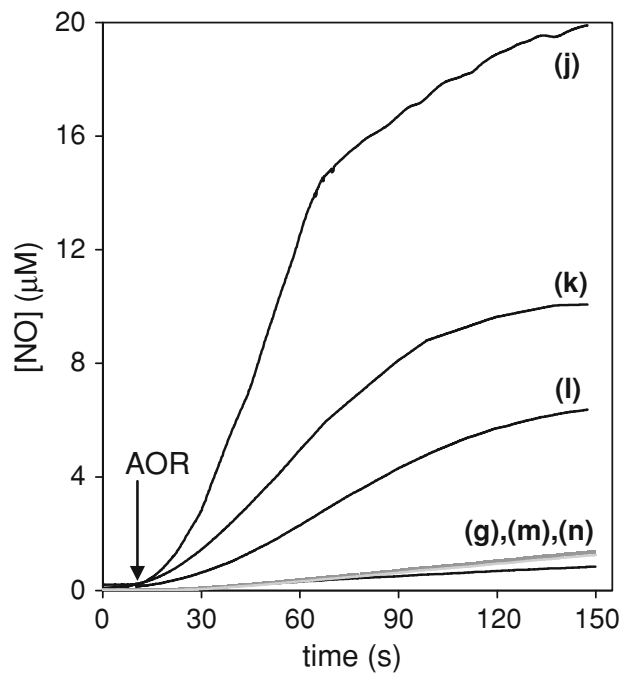

arrow and the NO decrease was followed (f). Right: The anaerobic AOR-catalysed NO formation during nitrite reduction by aldehyde was assayed in the presence of $1.00 \mathrm{mM}(l), 10.0 \mathrm{mM}(k)$ and $200 \mathrm{mM}(j)$ nitrite and $50 \mu \mathrm{M}(k, l)$ and $500 \mu \mathrm{M}(j)$ benzaldehyde, with $1.00 \mu \mathrm{M}(k, l)$ or $2.50 \mu \mathrm{M}(j)$ AOR. In all cases, the reactions were initiated by the addition of $\mathrm{XO}$ or AOR at the point indicated by the arrow. Control curves performed in the absence of enzyme (g) (with $25 \mathrm{mM}$ nitrite and $250 \mu \mathrm{M}$ aldehyde), aldehyde (with $25 \mathrm{mM}$ nitrite and $1.00 \mu \mathrm{M}$ XO $(h)$ or AOR $(m)$ ) and nitrite (with $250 \mu \mathrm{M}$ aldehyde and $1.00 \mu \mathrm{M}$ XO $(i)$ or AOR $(n))$ are also represented 
Steady-state kinetics of nitrite reduction catalysed by $\mathrm{XO}$ and $\mathrm{AOR}$

The anaerobic nitrite reduction was, subsequently, kinetically characterised, following the XO- and AOR-catalysed NO formation, in the presence of dihydroxybenzaldehyde and benzaldehyde as reducing substrates, respectively. The initial rates of NO formation were determined with the NOselective electrode, as this method provides simple, continuous and direct measurements of the NO concentration as

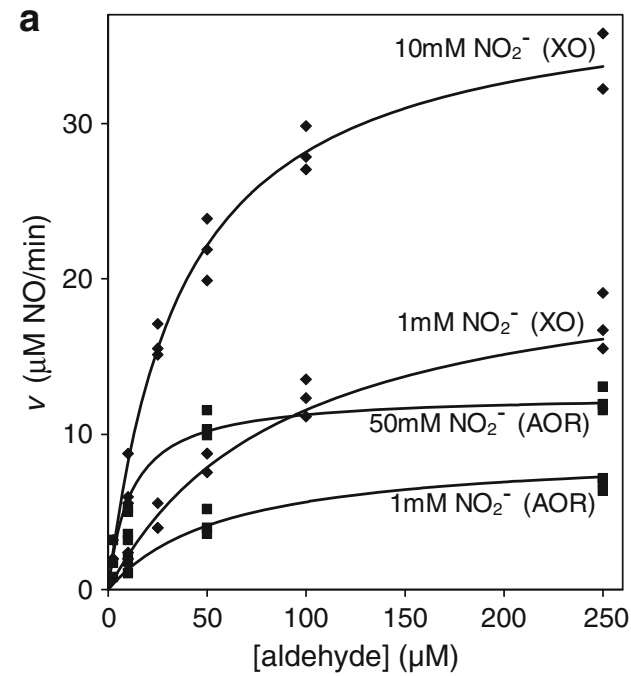

Fig. 3 Kinetics of NO formation catalysed by XO (diamonds) and AOR (squares). The initial rates of NO formation were measured with the NO-selective electrode, in $50 \mathrm{mM}$ phosphate buffer, $\mathrm{pH}$ 7.4. a The effect of aldehyde concentration on the initial rate of NO formation during the reduction of nitrite at the concentrations indicated. $\mathbf{b}$ The a function of time. To kinetically characterise the nitrite reduction, several assays were carried out, each at a different fixed nitrite concentration (treated as a single-substrate experiment), in which the apparent kinetic parameters were determined after measuring the initial rate of NO formation as a function of aldehyde concentration. For example, the individual results observed in the presence of 1, 10 and $50 \mathrm{mM}$ nitrite and 10 and $50 \mu \mathrm{M}$ aldehyde are shown in Fig. 3, and the calculated apparent kinetic parameters are summarised in Table 1. Within the concentrations assayed,

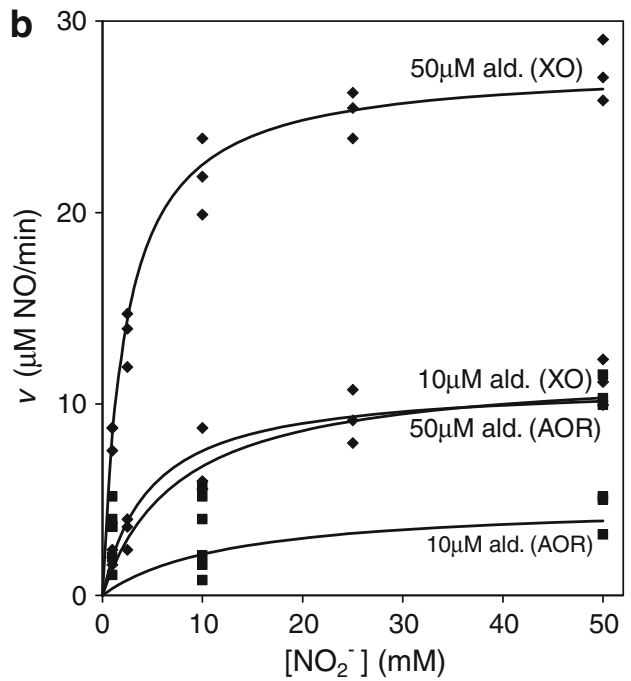

effect of nitrite concentration on the initial rate of NO formation during the oxidation of aldehyde at the concentrations indicated. Dihydroxybenzaldehyde and benzaldehyde were the aldehydes used with XO and AOR, respectively. The hyperbolic curves shown were generated with the apparent kinetic parameters given in Table 1

Table 1 AOR and XO kinetic parameters for NO formation during nitrite reduction in the presence of aldehyde

\begin{tabular}{|c|c|c|c|c|c|}
\hline \multicolumn{6}{|c|}{ Apparent kinetic parameters } \\
\hline & $k_{\mathrm{cat}}^{\text {app }}$ aldehyde $\left(\mathrm{s}^{-1}\right)$ & $K_{\mathrm{m}}^{\text {app }}$ aldehyde $(\mu \mathrm{M})$ & & $k_{\text {cat }}^{\text {app }}$ nitrite $\left(\mathrm{s}^{-1}\right)$ & $K_{\mathrm{m}}^{\mathrm{app}}$ nitrite $(\mathrm{mM})$ \\
\hline \multicolumn{6}{|l|}{ AOR } \\
\hline Nitrite $1 \mathrm{mM}$ & 0.0748 & 59.0 & Aldehyde $10 \mu \mathrm{M}$ & 0.0407 & 12.8 \\
\hline Nitrite $50 \mathrm{mM}$ & 0.105 & 11.7 & Aldehyde $50 \mu \mathrm{M}$ & 0.0991 & 7.63 \\
\hline \multicolumn{6}{|l|}{$\mathrm{XO}$} \\
\hline Nitrite $1 \mathrm{mM}$ & 0.365 & 89.3 & Aldehyde $10 \mu \mathrm{M}$ & 0.185 & 4.70 \\
\hline Nitrite $10 \mathrm{mM}$ & 0.645 & 37.3 & Aldehyde $50 \mu \mathrm{M}$ & 0.461 & 2.29 \\
\hline
\end{tabular}

Kinetic parameters

\begin{tabular}{|c|c|c|c|c|c|}
\hline & $k_{\text {cat }}\left(\mathrm{s}^{-1}\right)$ & $K_{\mathrm{m}}$ aldehyde $(\mu \mathrm{M})$ & $K_{\mathrm{m}}$ nitrite $(\mathrm{mM})$ & $K_{\mathrm{i}}$ aldehyde $(\mu \mathrm{M})$ & \\
\hline $\mathrm{XO}$ & 0.693 & 23.0 & 0.585 & 325 & Ternary-complex mechanism \\
\hline AOR & 0.244 & 16.4 & 4.15 & 55.2 & \\
\hline
\end{tabular}

The initial rates of NO formation were measured with the NO-selective electrode, in $50 \mathrm{mM}$ phosphate buffer, pH 7.4. Dihydroxybenzaldehyde and benzaldehyde were the aldehydes used with XO and AOR, respectively. The apparent kinetic parameters for nitrite and aldehyde were obtained in the presence of the substrate concentrations indicated. The real kinetic parameters were determined with the secondary plots shown in Fig. $4 \mathrm{c}$ and d. For a ternary-complex mechanism, $K_{\mathrm{i}}^{\text {aldehyde }}$ is equivalent to $K_{\mathrm{m}}$ for very low nitrite concentrations and is the true equilibrium dissociation constant of the enzyme-aldehyde complex 
both AOR and XO reactions followed Michaelis-Menten kinetics, with no evidence of substrate inhibition (no initial rate decrease with increasing substrate concentrations). The apparent kinetic parameters of XO are in good agreement with those reported by $\mathrm{Li}$ et al. [23], in particular the value of $K_{\mathrm{m}}^{\mathrm{app}}$ for nitrite $(2.29 \mathrm{mM})$ that $\mathrm{Li}$ et al. found to be $2.4 \pm 0.2 \mathrm{mM}$ independently of the nature of the reducing substrate $(40 \mu \mathrm{M}$ aldehyde, $5 \mu \mathrm{M}$ xanthine or $1 \mathrm{mM}$ $\mathrm{NADH})$.

Two primary plots for XO are represented in Fig. 4a and b. A Lineweaver-Burk plot with no parallel lines and a Hanes plot with lines that intersect at negative values indicate that nitrite reduction follows a ternary-complex mechanism, with Eq. 5 as the rate equation [41]. Since the kinetic assays were conducted in the absence of added products, it was not possible to determine if the binding of substrates is ordered or random. However, it is plausible that the aldehyde, like xanthine [43, 44], reacts only with enzyme molecules with $\mathrm{Mo}^{6+}$. On the other hand, because the EPR spectra (described later) did not give any evidence for the nitrite interaction with $\mathrm{Mo}^{6+}$, it is probable that the nitrite binds only to reduced molybdenum. Thus, it is conceivable that the aldehyde is the first substrate to bind (to the oxidised molybdenum), with nitrite binding second, only after molybdenum reduction. Concerning the products, because both oxidation and reduction half-reactions occur at the molybdenum centre (as described later), it seems likely that the carboxylate must first leave the enzyme for nitrite to be reduced. For these reasons, we suggest that the nitrite reduction occurs through the formation of a "carboxylate-enzyme-nitrite" complex, with the aldehyde being the first substrate to bind and NO the last product to leave the enzyme (a compulsory-order ternary-complex mechanism, as schematically represented above Eq. 5).
NO formation by both enzymes and allow a direct comparison between the two enzymes to be made. As expected from the individual results (Figs. 2, 3), the specificity constant of AOR for nitrite $\left(0.0588 \mathrm{~s}^{-1} \mathrm{mM}^{-1}\right)$ was found to be not as high as the XO constant $\left(1.18 \mathrm{~s}^{-1} \mathrm{mM}^{-1}\right)$, whereas the specificity constants for the aldehyde were comparable (14.9 and $30.1 \mathrm{~s}^{-1} \mathrm{mM}^{-1}$, respectively). Nevertheless, as long as the nitrite concentration is high enough, the rate of $\mathrm{NO}$ formation by AOR could attain values similar to those of mammalian $\mathrm{XO}$.

Participation of $\mathrm{XO}$ and AOR redox centres in nitrite reduction

To gain insight into what happens in the $\mathrm{XO}$ and $\mathrm{AOR}$ redox centres (molybdenum, $\mathrm{Fe} / \mathrm{S}$ and FAD) during nitrite reduction, the reactions with nitrite and NO were followed by EPR spectroscopy.

First, the interaction of NO with the enzymes was studied by adding pure NO (solution saturated with NO gas) to XO and AOR samples reduced with aldehyde or dithionite. The EPR spectra of those four samples showed, besides the characteristic $\mathrm{Mo}^{5+}$-rapid type, $\mathrm{Fe} / \mathrm{S}$ and $\mathrm{FADH}^{\bullet}$ signals (the last one only in $\mathrm{XO}$ ), one axial signal at $g_{\perp}=2.04$ and $g_{/ /}=2.015$ (data not shown). This axial signal was attributed to a non-haem iron-dinitrosyl complex, on the basis of the large amount of information accumulated for over 50 years of extensive use of $\mathrm{NO}$ as a spectroscopic probe for iron-containing proteins [45, 46]. In the case of $\mathrm{XO}$ and $\mathrm{AOR}$, the axial signal must arise from a dinitrosyl-Fe/S complex (Fe/S-NO), formed through the reaction between $\mathrm{NO}$ and the reduced $\mathrm{Fe} / \mathrm{S}$. The addition of NO to oxidised enzymes produced no signals, until a reducer (aldehyde or dithionite) was added

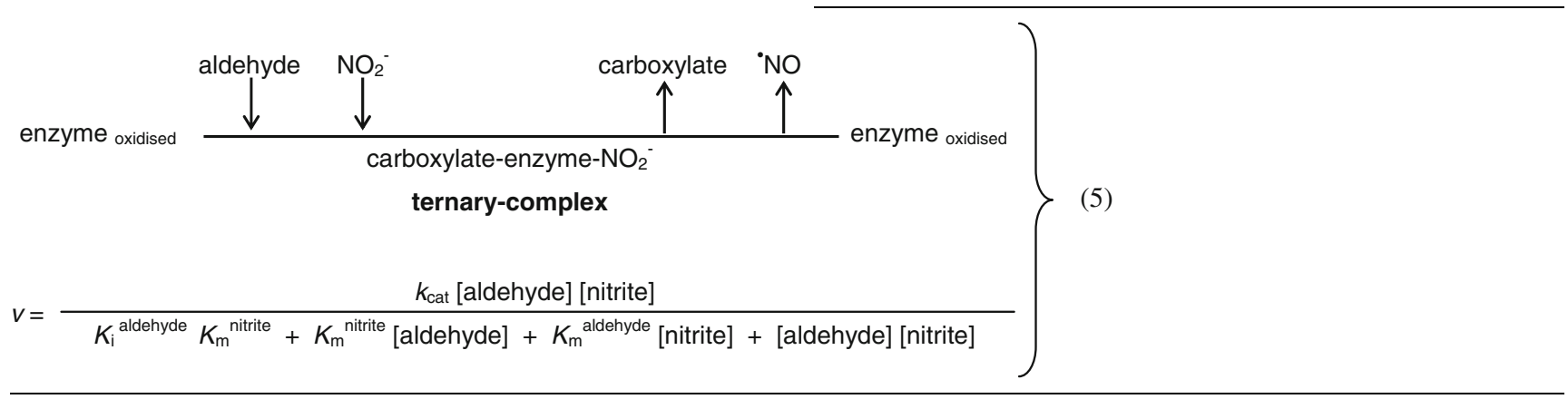

The real kinetic parameters were determined with the secondary plots shown in Fig. 4c and d [41]. The kinetic parameters summarised in Table 1 describe the kinetics of and the $\mathrm{Mo}^{5+}, \mathrm{Fe} / \mathrm{S}, \mathrm{Fe} / \mathrm{S}-\mathrm{NO}$ and $\mathrm{FADH}^{\bullet}$ signals appeared, demonstrating that the NO reacts only with reduced $\mathrm{Fe} / \mathrm{S}$, as expected. Concerning the molybdenum 

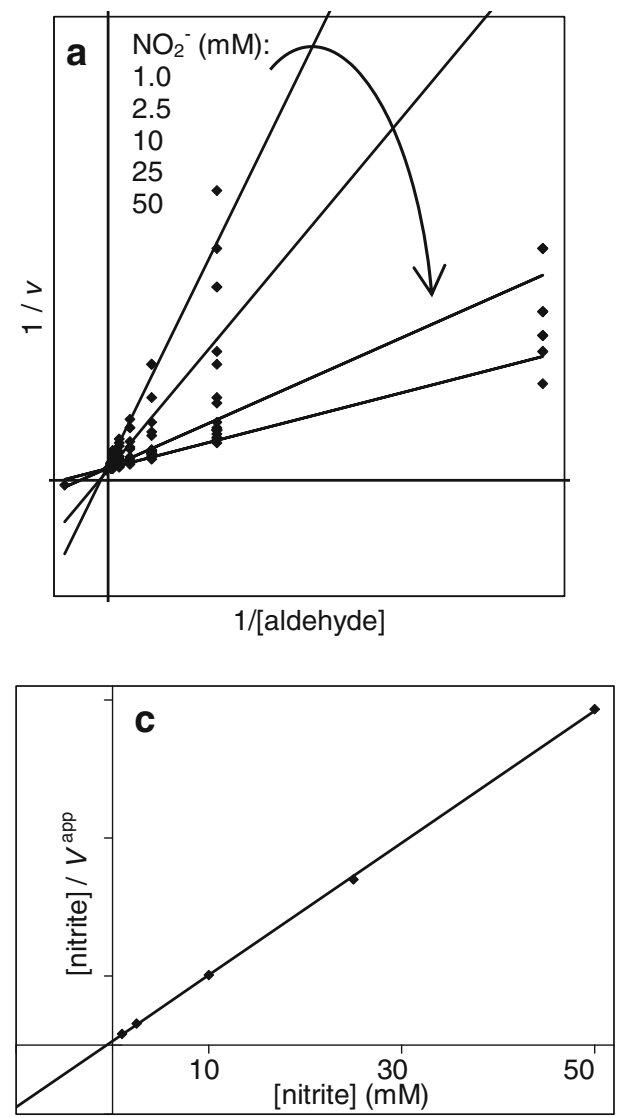

Fig. 4 Kinetics of NO formation catalysed by XO. Lineweaver-Burk (a) and Hanes (b) plots of the initial rates of XO-catalysed NO formation, suggesting a ternary-complex reaction mechanism. The

and flavin, it should be noted that the NO treatment (either before or after the reducer addition) caused no modification of the $\mathrm{Mo}^{5+}$ (a rapid type 1) and $\mathrm{FADH}^{\bullet}$ signals, even after $1 \mathrm{~h}$ incubation. In particular, it should be emphasised that no conversion to a $\mathrm{Mo}^{5+}$-slow type signal was ever observed. The slow signal arises from desulfo- $\mathrm{XO}$ molecules (i.e. molecules in which the essential $\mathrm{Mo}=\mathrm{S}$ was replaced by a $\mathrm{Mo}=\mathrm{O}$ group $[47,48]$ ) and its absence demonstrates that the added $\mathrm{NO}$ does not react with the essential molybdenum sulfido group under our assay conditions.

Once the reaction of NO with the enzymes redox centres had been established, the nitrite reaction study was initiated. First, the XO and AOR were reduced with aldehyde, to develop the characteristic $\mathrm{Fe} / \mathrm{S}$ (observed at $20 \mathrm{~K}$ ), $\mathrm{Mo}^{5+}$ and $\mathrm{FADH}^{\bullet}$ signals (observed at both 20 and $100 \mathrm{~K}$ ) (Fig. 5, spectra a). After the addition of nitrite, the intensity of all signals began to decrease (Fig. 5, spectra $b, c)$, as the enzymes became oxidised. Simultaneously, the NO formed started to bind to the reduced $\mathrm{Fe} /$ $\mathrm{S}$, and the axial signal characteristic of the $\mathrm{Fe} / \mathrm{S}-\mathrm{NO}$
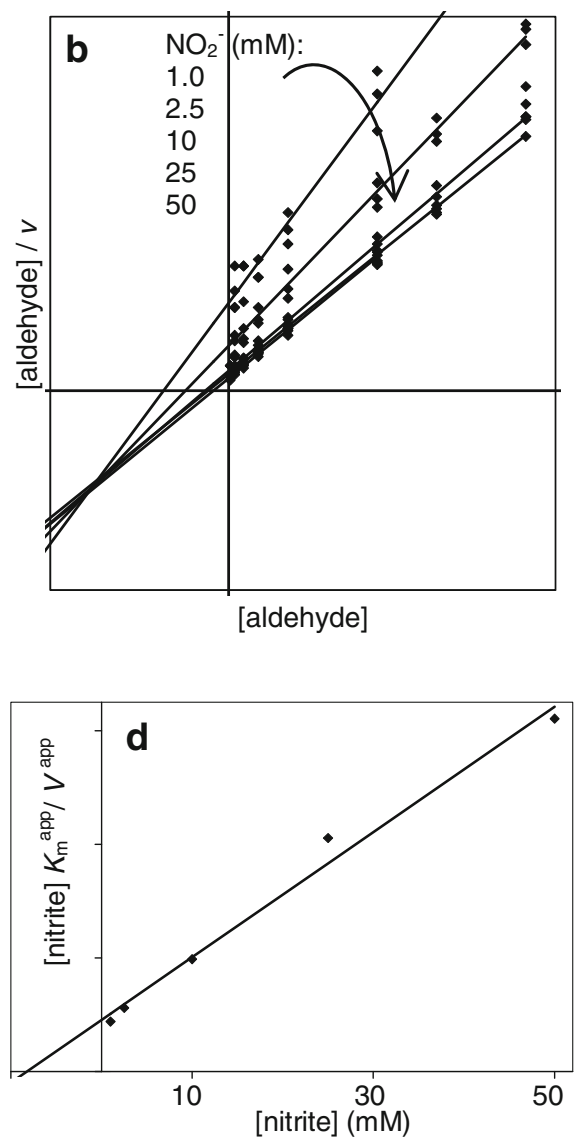

secondary plots (according to Eq. 5) for the determination of the real kinetic parameters presented in Table 1 are shown in $\mathbf{c}\left(r^{2}=0.999\right)$ and $\mathbf{d}\left(r^{2}=0.987\right)$

emerged. In fact, the presence of the $\mathrm{Fe} / \mathrm{S}-\mathrm{NO}$ signal is additional proof that $\mathrm{NO}$ is being formed during the nitrite reduction catalysed by XO and AOR. At this point, the addition of more aldehyde led to the re-reduction of the enzymes and to the reappearance of the $\mathrm{Mo}^{5+}, \mathrm{Fe} / \mathrm{S}$, $\mathrm{Fe} / \mathrm{S}-\mathrm{NO}$ and $\mathrm{FADH}^{\bullet}$ signals (Fig. 5, spectra d). After this second aldehyde addition, the $\mathrm{Mo}^{5+}, \mathrm{Fe} / \mathrm{S}$ and FADH $^{\bullet}$ signals began to decrease once again, at the same time as more nitrite was reduced (Fig. 5, spectra e). The addition of nitrite to oxidised enzymes resulted in no EPR signals, and only after the addition of aldehyde did the signals begin to arise, suggesting that the nitrite does not interact with oxidised enzymes. The same results were obtained when the enzymes were reduced with xanthine, NADH (only XO) or dithionite (both AOR and XO), either before or after the nitrite addition (data not shown). In all situations, the presence of nitrite never changed the form of the $\mathrm{Mo}^{5+}$-rapid, $\mathrm{Fe} / \mathrm{S}$ or $\mathrm{FADH}^{\bullet}$ signals and, once more, the spectra obtained indicated that the NO enzymatically formed does not react with the essential molybdenum sulfido group. 
Fig. 5 XO-catalysed (top) and AOR-catalysed (bottom) nitrite reduction followed by EPR spectroscopy at $20 \mathrm{~K}$ (left) and $100 \mathrm{~K}$ (right). XO and AOR were first reduced with aldehyde (enzyme/aldehyde 1:10, for 2-3 $\min (a)$ ), to develop the characteristic $\mathrm{Fe} / \mathrm{S}, \mathrm{Mo}^{5+}$ and $\mathrm{FADH}^{\bullet}$ signals (FADH ${ }^{\bullet}$ only in $\mathrm{XO})$. Nitrite was then added (enzyme/nitrite 1:200) and allowed to react for $1 \mathrm{~min}$ (b) and $30 \mathrm{~min}(c)$, until the enzymes became almost completely oxidised. The subsequent addition of more aldehyde (enzyme/aldehyde $1: 10$, for $1 \mathrm{~min}(d))$ led to the reappearance of the $\mathrm{Mo}^{5+}, \mathrm{Fe} / \mathrm{S}$, $\mathrm{Fe} / \mathrm{S}-\mathrm{NO}$ and $\mathrm{FADH}^{\bullet}$ signals.

The signals began to decrease once again, at the same time as nitrite was being reduced (spectra $e$ taken 30 min after the aldehyde addition). The X-band EPR spectra were acquired as described in "EPR assays", with a modulation amplitude of $0.5 \mathrm{mT}$ and a microwave power of $633 \mu \mathrm{W}$
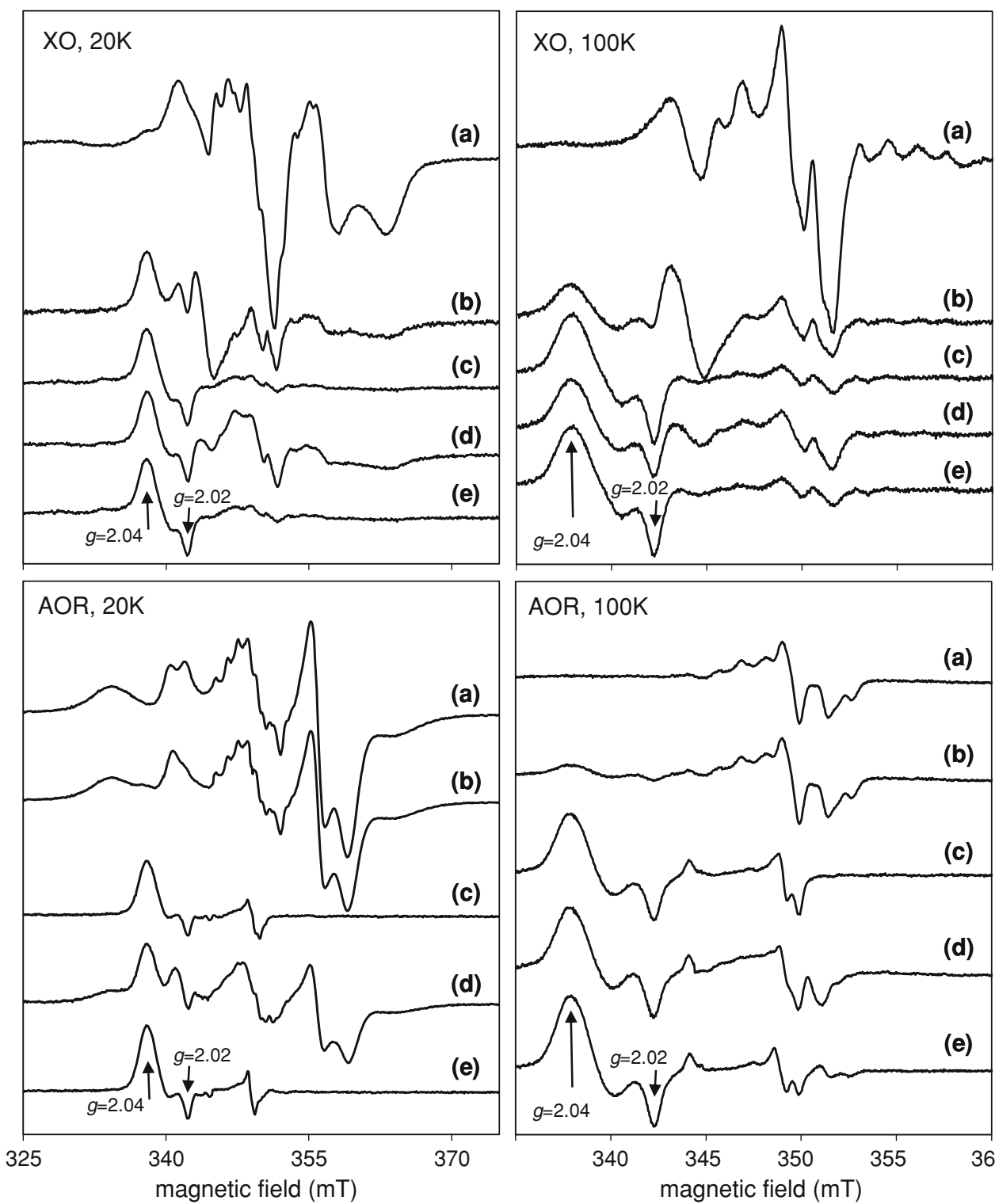

AOR, $100 \mathrm{~K}$

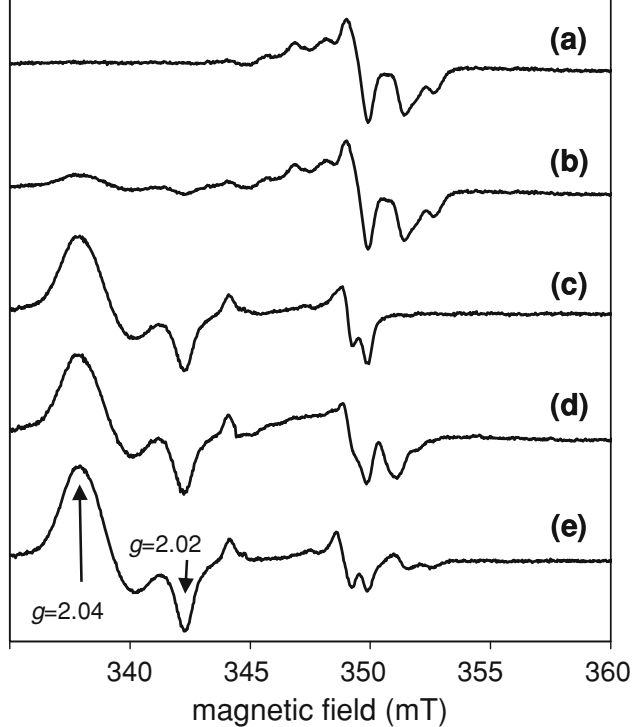

The observed "redox cycles" (reduction $\rightarrow$ oxidation $\rightarrow$ reduction...) indicate that all the AOR and XO redox centres can participate in the electron delocalisation during catalysis, and that nitrite reacts only with reduced enzymes. Nevertheless, none of the EPR spectra provided direct evidence for the interaction of the nitrite with the molybdenum, flavin or $\mathrm{Fe} / \mathrm{S}$, and the question of the site of nitrite reduction prevailed. To answer that question, the nitrite reduction was studied in the presence of two molybdenum site-specific inhibitors (that do not interfere with the oxidationreduction of other redox centres), the allopurinol and ethylene glycol.

Allopurinol ( $1 H$-pyrazolo[3,4- $d$ ]pyrimidine-4-ol), a structural isomer of hypoxanthine, is a potent $\mathrm{XO}$ inhibitor. $\mathrm{XO}$ hydroxylates allopurinol to oxypurinol $(1 H$-pyrazolo[3,4- d]pyrimidine-4,6-diol), which binds tightly to the reduced molybdenum, blocking it and inhibiting the XO hydroxylase activity [40, 49, 50]. The formation of the oxypurinolXO complex, however, does not interfere with any reaction occurring at the two $\mathrm{Fe} / \mathrm{S}$ or at the FAD site, as shown by the NADH oxidation by molecular oxygen (which occurs at the flavin site) in the presence of the inhibitor [51]. Therefore, the Fe/S and FAD of allopurinol-inhibited XO can be reduced with NADH, in spite of the molybdenum being blocked. In view of that, if nitrite reduction occurs at the $\mathrm{Fe} / \mathrm{S}$ or flavin sites, then the NADH-reduced $\mathrm{XO}$ would be able to reduce nitrite in the presence of allopurinol. To test this hypothesis, the ability of allopurinol-inhibited XO to catalyse the nitrite reduction was evaluated by EPR spectroscopy. Allopurinol-reacted XO (Fig. 6, spectra a) 


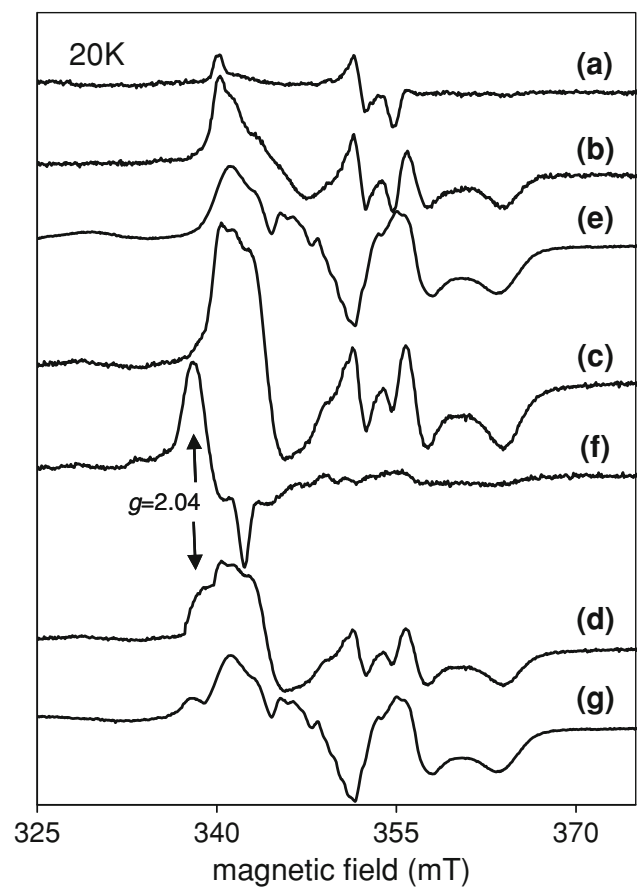

Fig. 6 Effect of allopurinol in XO-catalysed nitrite reduction probed by EPR spectroscopy at $20 \mathrm{~K}(l e f t)$ and $100 \mathrm{~K}$ (right) - comparison with not inhibited enzyme. XO was first reacted with allopurinol (enzyme/allopurinol 1:10, for $30 \mathrm{~min}$ ) to develop the characteristic inhibited signal $(a)$. The enzyme was then further reduced with NADH (enzyme/NADH 1:10, for 2-3 min) to give rise to the Fe/S and $\mathrm{FADH}^{\bullet}$ signals $(b)$. The inhibited reduced-XO was then mixed with nitrite (enzyme/nitrite 1:200, for $30 \mathrm{~min}$ ), but the resulting spectra $(c)$ were identical to the previous ones (apart from an increase in the $\mathrm{FADH}^{\bullet}$ signal intensity), showing that the enzyme was not oxidised by nitrite and that $\mathrm{Fe} / \mathrm{S}-\mathrm{NO}$ was not formed, in spite of the $\mathrm{Fe} / \mathrm{S}$ and flavin being reduced. When $\mathrm{NO}$ was added to a sample of

displayed the characteristic EPR signal [48] and, after $\mathrm{NADH}$ addition, the $\mathrm{FADH}^{\bullet}$ and $\mathrm{Fe} / \mathrm{S}$ signals emerged (Fig. 6, spectra b), confirming that allopurinol-inhibited $\mathrm{XO}$ can have its $\mathrm{Fe} / \mathrm{S}$ and flavin reduced. The subsequent addition of nitrite to inhibited $\mathrm{XO}$, however, did not elicit the enzyme oxidation or the $\mathrm{Fe} / \mathrm{S}-\mathrm{NO}$ formation (Fig. 6, spectra c). To demonstrate that the Fe/S were not affected by the presence of allopurinol, pure $\mathrm{NO}$ was added to a sample of allopurinol-inhibited NADH-reduced XO, resulting in the formation of the expected $\mathrm{Fe} / \mathrm{S}-\mathrm{NO}$ signal (Fig. 6, spectra d). It should be noted that, under the same conditions, the not inhibited (native) NADH-reduced enzyme is promptly oxidised by nitrite, with $\mathrm{Fe} / \mathrm{S}-\mathrm{NO}$ formation (Fig. 6, spectra e-g). In addition to the spectroscopic studies, the complete inhibition of NO formation by allopurinol was also demonstrated with the NOselective electrode, regardless of the reducing substrate chosen (NADH, xanthine or aldehyde). These results demonstrate that the XO-catalysed nitrite reduction is

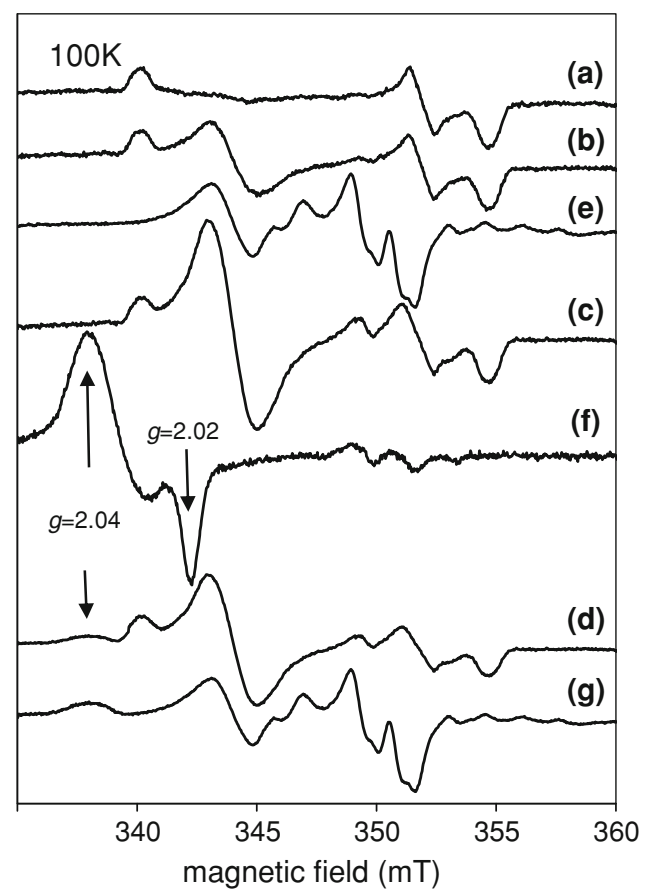

allopurinol-inhibited NADH-reduced $\mathrm{XO}$, the spectra showed the $\mathrm{Fe} / \mathrm{S}-\mathrm{NO}$ signal $(d)$, confirming that, if NO was formed, it would give rise to the Fe/S-NO signal. One tube of not inhibited (native) NADHreduced $\mathrm{XO}$ was treated alongside with the allopurinol-inhibited sample. Apart from the $\mathrm{Mo}^{5+}$-rapid signal, the spectra of native $\mathrm{NADH}$-reduced $\mathrm{XO}(e)$ were similar to the allopurinol-inhibited $\mathrm{NADH}$-reduced XO ones $(b)$. However, the native enzyme was promptly oxidised by nitrite and the $\mathrm{NO}$ formed gave rise to the $\mathrm{Fe} / \mathrm{S}$ NO signal $(f)$. The addition of NO to native NADH-reduced $\mathrm{XO}$ also resulted in the $\mathrm{Fe} / \mathrm{S}-\mathrm{NO}$ signal formation $(g)$. The X-band EPR spectra were acquired as described in "EPR assays", with a modulation amplitude of $0.5 \mathrm{mT}$ and a microwave power of $633 \mu \mathrm{W}$

dependent on the presence of an accessible (not blocked) molybdenum centre.

The same reasoning was applied to determine the AOR site of nitrite reduction, but because allopurinol does not inhibit AOR, a spectroscopic study of the AOR and XO ethylene glycol inhibition was undertaken. Addition of ethylene glycol (1,2-ethanediol) gives rise to a characteristic $\mathrm{Mo}^{5+}$ rhombic signal that is resistant to both oxidation and reduction $[52,53]$. The signal is thought to arise from a complex (where the inhibitor is covalently bound to the molybdenum through two oxygen atoms) that blocks the molybdenum atom, without affecting the reduction of the $\mathrm{Fe} / \mathrm{S}$ and flavin, in a similar way as allopurinol does. The EPR spectra of ethylene glycol treated dithionite-reduced AOR and XO (not shown) exhibited the expected inhibited signal along with the $\mathrm{FADH}^{\bullet}$ (only in $\mathrm{XO}$ ) and $\mathrm{Fe} / \mathrm{S}$ signals. The subsequent addition of nitrite did not result in the AOR or XO oxidation or in the formation of the Fe/S- 
NO signal. Together, the allopurinol and ethylene glycol inhibition studies described prove that nitrite binding and reduction take place at the XO molybdenum centre.

To investigate if the molybdenum sulfido group is required for nitrite reduction, one sample of desulfo-XO was prepared by reacting the native $\mathrm{XO}$ with cyanide, as described in "Enzyme samples" [47, 48]. Whereas the native sulfoenzyme promptly triggered the NO formation in the presence of either aldehyde or NADH (Fig. 2), the desulfo-XO was unable to catalyse the nitrite reduction, with any reducing substrate (xanthine, aldehyde or NADH, data not shown). The EPR spectra of the NADH-reduced desulfo-XO displayed the characteristic $\mathrm{Fe} / \mathrm{S}$ and $\mathrm{FADH}^{\bullet}$ signals and the expected $\mathrm{Mo}^{5+}$-slow signal (Fig. 7, spectra a). However, the addition of nitrite neither oxidises the enzyme nor leads to the formation of $\mathrm{Fe} / \mathrm{S}-\mathrm{NO}$ (Fig. 7, spectra b). The addition of pure NO to reduced desulfo-XO resulted in the formation of the characteristic Fe/SNO signal (Fig. 7, spectra c), as expected. Under the same conditions, the NADH-reduced sulfoenzyme was promptly oxidised by nitrite, with $\mathrm{Fe} / \mathrm{S}-\mathrm{NO}$ formation (Fig. 7, spectra $\mathrm{d}-\mathrm{f}$ ). The comparison of the results obtained with desulfo$\mathrm{XO}$ and sulfo-XO demonstrates that the molybdenum sulfido group is necessary for the $\mathrm{XO}$-catalysed nitrite reductase activity.

A similar assay was attempted with an AOR sample. However, after incubation with cyanide followed by gel filtration, the AOR sample retained both the benzaldehyde oxidase activity (as was observed and discussed in [25]) and nitrite reductase activity.

\section{Discussion}

AOR and XO-catalysed nitrite reduction to NO

The reduction of nitrate to nitrite by milk, in the presence of aldehydes, was first described at the beginning of the twentieth century, but only in 1924 did Dixon and Thurlow [17] identify the milk component responsible for that activity. Later, XO-catalysed nitrate reduction was further

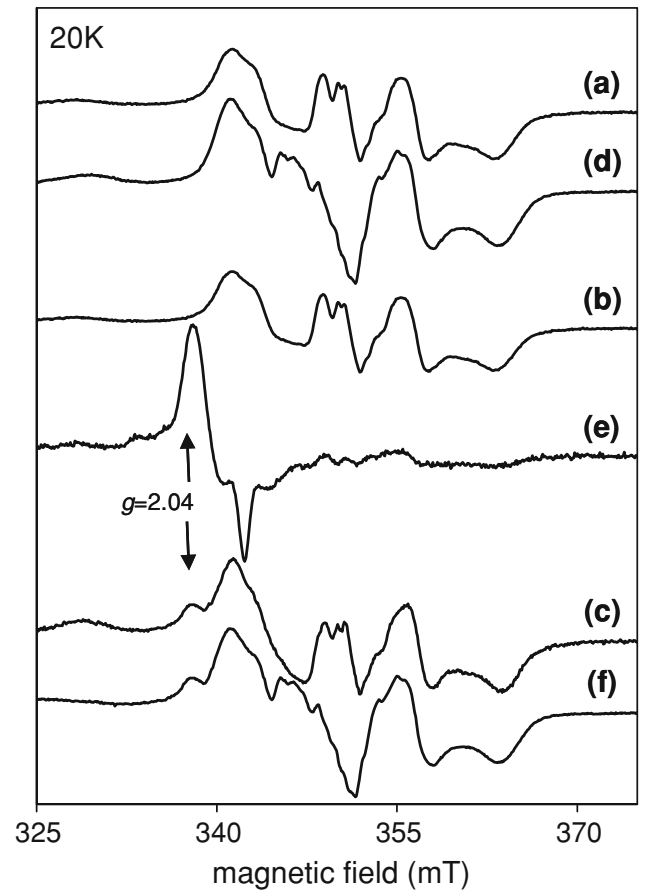

Fig. 7 Effect of the XO molybdenum sulfido group in nitrite reduction probed by EPR spectroscopy at $20 \mathrm{~K}$ (left) and $100 \mathrm{~K}$ (right) - comparison between sulfo-XO and desulfo-XO. Native (d) and desulfo-XO (a) were first reduced with NADH (enzyme/ NADH 1:10, for $30 \mathrm{~min}$ ) to develop the characteristic $\mathrm{Mo}^{5+}$-rapid (sulfo-XO) and $\mathrm{Mo}^{5+}$-slow (desulfo-XO) signals along with the $\mathrm{Fe} / \mathrm{S}$ and $\mathrm{FADH}^{\bullet}$ signals. Nitrite was then added (enzyme/nitrite 1:200, for $30 \mathrm{~min}$ ), and, whereas the sulfo-XO was almost completely oxidised $(e)$, the desulfo-XO spectra obtained $(b)$ were identical to the previous

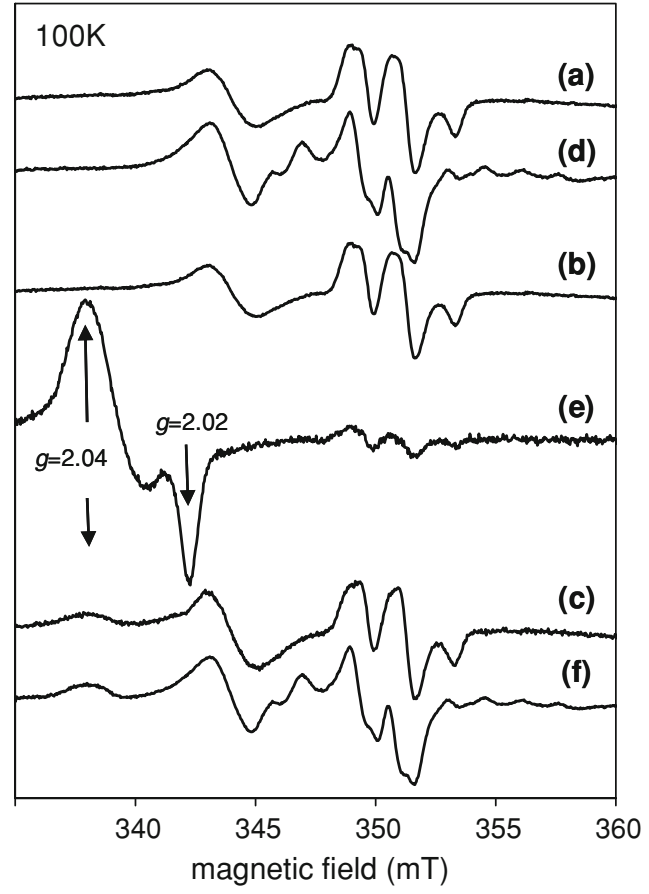

ones $(a)$, showing that the enzyme was not oxidised by nitrite and that $\mathrm{Fe} / \mathrm{S}-\mathrm{NO}$ was not formed, in spite of the $\mathrm{Fe} / \mathrm{S}$ and flavin being reduced. When NO was added to a sample of NADH-reduced desulfo-XO, the spectra showed the Fe/S-NO signal (c), confirming that if $\mathrm{NO}$ was formed, it would give rise to the $\mathrm{Fe} / \mathrm{S}-\mathrm{NO}$ signal. The addition of $\mathrm{NO}$ to NADH-reduced sulfo-XO also resulted in the $\mathrm{Fe} / \mathrm{S}-$ NO signal formation $(f)$. The X-band EPR spectra were acquired as described in "EPR assays", with a modulation amplitude of $0.5 \mathrm{mT}$ and a microwave power of $633 \mu \mathrm{W}$ 
studied by a few groups $[18,19]$. This activity was then "forgotten" until the late 1990s, when the (patho) physiological importance of the generated NO was realised by the groups of Blake, Harrison, Zweier and others [20-28] who restudied the nitrate and nitrite reduction. The detailed molecular mechanism of both reductions, however, remains to be elucidated. Those works prompted us to study the molecular mechanism of nitrite reduction and to investigate if this nitrite reductase activity is common to other enzymes of the XO family, namely to non-eukaryotic enzymes.

The results presented in this work corroborated [22-28] the mammalian XO-catalysed nitrite reduction and demonstrated, for the first time, that the prokaryotic D. gigas AOR does catalyse the nitrite reduction to $\mathrm{NO}$ in the presence of an electron donor to the enzyme, substrate (aldehyde) or not (dithionite) (Figs. 1, 2, 3). Providing that the available nitrite concentration is high enough, the steady-state kinetic characterisation (Table 1) showed that the AOR can catalyse the NO formation at rates comparable to the mammalian $\mathrm{XO}$ ones.

\section{Site of nitrite reduction}

Iron is the metal most prevalently used in nitrite reduction ( $c d_{1}$ haem-dependent nitrite reductase, $b$-haem-containing haemoglobin, myoglobin and neuroglobin, haem-containing cytochrome $\mathrm{P}_{450}$ and mitochondrial respiratory chain cytochromes), whereas copper is found in the copperdependent nitrite reductases. It is also relevant to mention that the specific endothelial NO synthase also reduces nitrite to NO, in an anaerobic reaction that is $b$-haemdependent (like the oxygen-dependent $\mathrm{L}$-arginine reaction) [54].

Once the XO- and AOR-catalysed nitrite reduction had been detected, it was mandatory to assign the metal responsible for catalysis. The Fe/S could be candidates, but nitrite reduction was shown by EPR spectroscopy to occur at the molybdenum centre. The EPR spectra of reduced XO and AOR showed that the native enzymes are promptly oxidised by nitrite and that the NO thus formed reacts with the reduced $\mathrm{Fe} / \mathrm{S}$ to give rise to the characteristic $\mathrm{Fe} / \mathrm{S}-\mathrm{NO}$ signal (Figs. 5, 6). Moreover, the primary source of reducing equivalents to reduce the molybdenum had no effect on the nitrite reduction, with any electron donor (substrate or not) being able to promote the nitrite reduction (Figs. 2, 5, 6). Simultaneously, the EPR spectra of ethylene glycol inhibited and allopurinol-inhibited (Fig. 6) reduced $\mathrm{XO}$ and AOR revealed that, although the molybdenum, $\mathrm{Fe} / \mathrm{S}$ and flavin centres were reduced, nitrite cannot oxidise the inhibited enzymes and no NO is formed. Together, these results prove unequivocally that the molybdenum is the direct electron donor to nitrite, and that nitrite binding and reduction is dependent on a "free" native reduced molybdenum centre.

Molecular mechanism of AOR- and XO-catalysed nitrite reduction to NO

During XO-catalysed aldehyde oxidation ${ }^{3}$ by molecular oxygen, one oxygen atom is transferred from water (the oxo group donor) to the aldehyde (the reducing substrate) to give the corresponding carboxylate (Eq. 6a), at the molybdenum centre (Scheme $1 \mathrm{~b}, \mathrm{i} \rightarrow$ iii) $[12,15$, 16]. The electrons thus introduced into the molybdenum are subsequently transferred to the Fe/S and FAD. At the flavin, the electrons are finally transferred to the molecular oxygen (the oxidising substrate) (Eq. 6b). During AOR catalysis, the same oxygen atom and electrons transfer are thought to occur, in spite of the fact that in this enzyme the electrons are transferred from the $\mathrm{Fe} / \mathrm{S}$ to a flavodoxin (the probable AOR oxidising substrate [38]). Accordingly, during molecular oxygen or flavodoxin reduction by an aldehyde, the XO or AOR molybdenum centre participates only in the oxidative half-reaction (Eq. 6a) of the overall catalytic cycle (Eq. 6a, b).

During XO- and AOR-catalysed nitrite reduction by an aldehyde, oxygen atom transfer must also take place, but in this case the oxygen atom transfer must occur in both directions. First, one oxygen atom is moved from the water (or other oxo group donor) to the aldehyde (Eq. 7a). After that, if NO is to be formed, another oxygen atom has to be transferred from nitrite to an oxo group acceptor, a water (Eq. 7b) or other molecule. In addition, electron transfer must also occur from the aldehyde (the reducing substrate) to nitrite (the oxidising substrate, equivalent to molecular oxygen or flavodoxin) (Eq. 7a, b). However, unlike the molecular oxygen or flavodoxin reduction, the nitrite reduction occurs unequivocally at the molybdenum centre. Furthermore, the steady-state kinetic study carried out puts forward the formation of a ternary complex, which is suggested to be a "carboxylate-enzyme-nitrite" complex. Therefore, during nitrite reduction by an aldehyde, the XO or AOR molybdenum centre must participate directly in both the oxidative and the reductive half-reactions (Eq. 7) of the overall catalytic cycle.

\footnotetext{
3 Although the molecular mechanism of XO-catalysed hydroxylation has been established for xanthine [7, 12, 15, 16], the underlying mechanism of aldehyde hydroxylation [8] (or of other substrate that is hydroxylated at the molybdenum site, such as FYX-051 [15]) is thought to be essentially the same.
} 
xanthine or aldehyde oxidation ${ }^{4}$ :

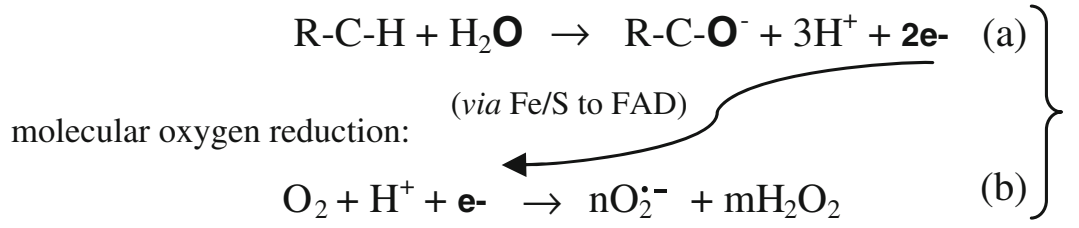

xanthine or aldehyde oxidation ${ }^{4}$ :

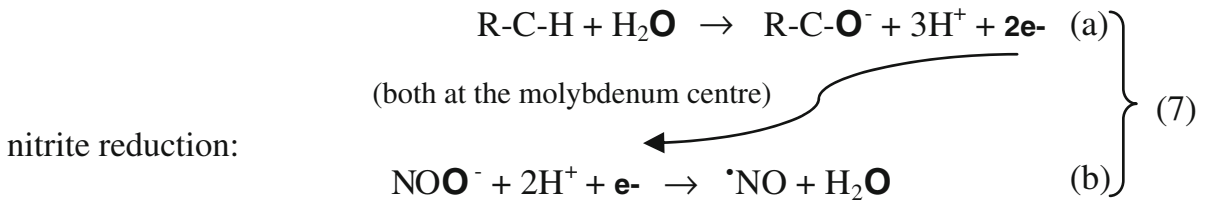

nitrite reduction by an aldehyde:

$\mathrm{R}-\mathrm{C}-\mathrm{H}+2 \mathrm{NOO}^{-}+\mathrm{H}^{+} \rightarrow \mathrm{R}^{-} \mathrm{C}-\mathrm{O}^{-}+2^{\circ} \mathrm{NO}+\mathrm{H}_{2} \mathrm{O}$

In view of that mandatory bidirectional oxygen transfer, which was established to occur at the molybdenum centre through the formation of a ternary complex, we suggest that the AOR- and XO-catalysed nitrite reduction by the aldehyde (Eq. 8) follows the mechanism depicted in Scheme 2. Accordingly, after molybdenum reduction by the aldehyde (Scheme 2, A $\rightarrow$ B), nitrite binds to the reduced molybdenum, displacing the carboxylate through the formation of a ternary "carboxylate- $\left(\mathrm{Mo}^{4+}\right)$-nitrite" complex (Scheme 2, C). Following nitrite reduction/ molybdenum oxidation, $\mathrm{NO}$ is released. Because nitrite reduction is a one-electron process (Eq. 7b), the molybdenum would end up in a 5+ oxidation state. The $\mathrm{p} K_{\mathrm{a}}$ of the coordinated ligands change dramatically with the molybdenum oxidation state, with the lower oxidation states possessing highly protonated ligands $[55,56]$. For this reason, both the oxygen and the sulfur atoms are depicted protonated, $\mathrm{Mo}^{5+}-\mathrm{OH}(-\mathrm{SH})($ Scheme 2, E), in a complex which would produce the characteristic $\mathrm{Mo}^{5+}$ rapid type EPR signal with two interacting protons. To generate a good leaving group (water, $\mathrm{Mo}^{5+}{ }_{-}{ }^{+} \mathrm{OH}_{2}$ ), the consumption of one proton is suggested (Scheme 2, $\mathrm{E} \rightarrow \mathrm{F}$, see also Eq. 8). Later, nitrite displaces the water molecule (Scheme 2, G $\rightarrow \mathrm{H}$ ) and, after a second cycle of nitrite reduction/molybdenum oxidation, the second $\mathrm{NO}$ molecule is released. The molybdenum is now in a $6+$

\footnotetext{
${ }^{4}$ For simplicity, xanthine ( $K_{\mathrm{a}}$ of 0.8 and 7.4) is represented in the neutral form. Urate ( $\mathrm{p} K_{\mathrm{a}}$ of 5.2 and 11.3) or carboxylate $\left(\mathrm{p} K_{\mathrm{a}}\right.$ of 4.2 for benzoic acid) is depicted in the physiological monoanionic form.
}

oxidation state, which would favour the deprotonation of its ligands [55, 56], and one proton is regenerated.

To account for the nitrite reduction by NADH or dithionite, one additional branch was included in Scheme 2, A $\rightarrow$ I. Dithionite reduces both enzymes, whereas NADH reduces only the $\mathrm{XO}$, through the FAD site, leading to molybdenum reduction through intramolecular electron transfer [51]. Once the molybdenum is reduced, $\mathrm{Mo}^{4+}-\mathrm{OH}_{2}(-\mathrm{SH})$ (Scheme 2, I), nitrite displaces the water molecule (Scheme $2, \mathrm{~J} \rightarrow \mathrm{D}$ ) and the mechanism of NO formation would follow as described above.

The kinetic data described herein point towards the formation of a ternary complex, indicating that both substrates must remain associated with the enzyme (Scheme 2, C) before the first product is released. However, the carboxylate release before nitrite binding (Scheme 2, B $\rightarrow$ I) could represent an important pathway under assay conditions different from ours, and for that reason it is also depicted in Scheme 2. In any case, all three pathways represented $(\mathrm{A} \rightarrow \mathrm{B} \rightarrow \mathrm{C} \rightarrow \mathrm{D}$ or $\mathrm{A} \rightarrow \mathrm{I} \rightarrow \mathrm{J} \rightarrow \mathrm{D}$ or $\mathrm{A} \rightarrow \mathrm{B} \rightarrow \mathrm{I} \rightarrow \mathrm{J} \rightarrow \mathrm{D}$ ) would lead to the formation of the same $\mathrm{Mo}^{4+}-\mathrm{ONO}(-\mathrm{SH})$ intermediate (D). After the formation of that nitrite-enzyme complex, the NO formation would follow the same mechanism $(\mathrm{D} \rightarrow \mathrm{E} \rightarrow \ldots \mathrm{A})$.

It should be noted that the mechanism described above suggests that the oxygen atoms from the two nitrite molecules are transferred to one water (Scheme 2, D $\rightarrow \mathrm{H}$ ) and to one carboxylate molecule (Scheme 2, H $\rightarrow$ A, see also Eq. 8). That is, the nitrite is suggested to act not only as an oxidising substrate, but also as an oxo group donor, a role that is played by the water in the "classical" aldehyde 


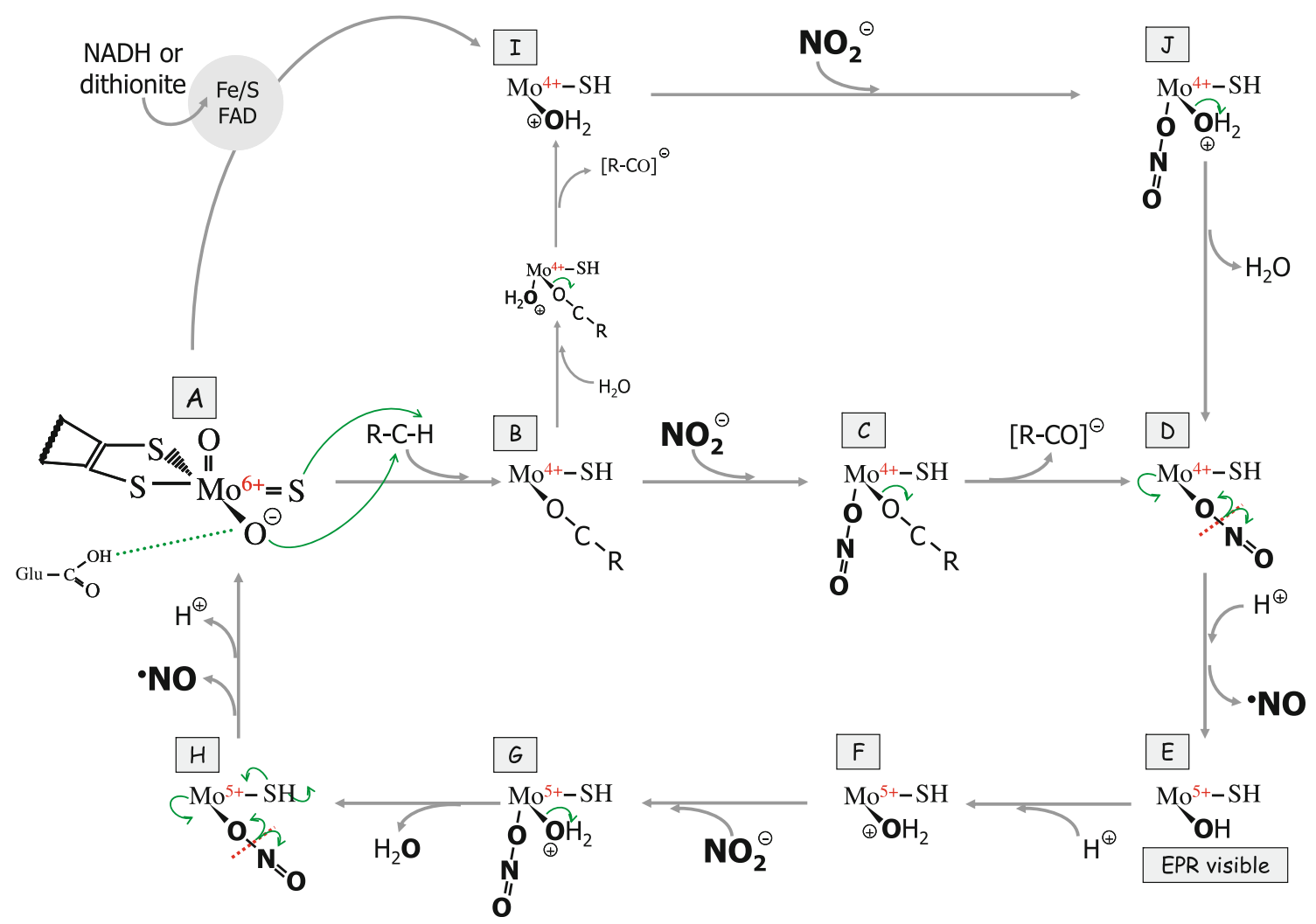

Scheme 2 Suggested mechanism of nitrite reduction by XO family enzymes. For simplicity, the complete molybdenum coordination sphere (omitting the pterin cofactor structure) is represented only for oxidised enzyme $(A)$. After molybdenum reduction by the aldehyde $(\mathrm{R}-\mathrm{CH})(A \rightarrow B)$, nitrite binds to reduced molybdenum $(C)$, displacing the carboxylate $\left(\mathrm{R}-\mathrm{CO}^{-}\right)$through the formation of a ternary complex. Following nitrite reduction/molybdenum oxidation, $\mathrm{NO}$ is released $(D \rightarrow E)$. The resulting enzyme $(E)$ would have the molybdenum atom in a $5+$ oxidation state in a complex which would produce the characteristic $\mathrm{Mo}^{5+}$-rapid type electron paramagnetic resonance $(E P R)$ signal with two interacting protons. To generate a good leaving group (water), the consumption of one proton is suggested $(E \rightarrow F)$. Later, nitrite displaces the water molecule $(G \rightarrow H)$ and, after a second cycle of nitrite reduction/molybdenum oxidation, the second $\mathrm{NO}$ molecule is released $(H \rightarrow A)$. To account for the nitrite reduction by NADH (only for XO) or dithionite (both $\mathrm{XO}$ and aldehyde oxidoreductase (AOR)), one additional branch $(A \rightarrow I)$ was included (FAD only in XO). Once the molybdenum is reduced $(I)$, nitrite displaces the water molecule $(J \rightarrow D)$ and the mechanism of NO formation follows as described above. The carboxylate release before nitrite binding $(A \rightarrow B \rightarrow I \rightarrow J)$ could represent an important pathway under assay conditions different from ours, and for that reason it was also depicted. $\mathrm{R}-\mathrm{CH}$ stands for an aldehyde or xanthine (in the neutral form), whereas $\mathrm{R}-\mathrm{CO}^{-}$ represents the respective carboxylate or urate (both in the physiological monoanionic form). Glu-C-OH $(=\mathrm{O})$ represents the glutamate residue thought to be responsible for the base-assisted catalysis (residue 1261 in $\mathrm{XO}$ and residue 869 in AOR) oxidation by molecular oxygen or flavodoxin (Scheme 1b, ii $\rightarrow$ iii). The water, on the other hand, is here suggested to be an oxo group acceptor along with the aldehyde. Even during nitrite reduction by NADH, the water should act as an oxo acceptor (accepting one oxygen atom from each nitrite molecule, Eq. 9):

nitrite reduction by NADH:

$\mathrm{NADH}+2 \mathrm{NOO}^{-}+3 \mathrm{H}^{+} \rightarrow \mathrm{NAD}^{+}+2{ }^{-} \mathrm{NO}+2 \mathrm{H}_{2} \mathbf{O}$

For the same reason, the $\mathrm{Mo}^{6+}$ cores are proposed to act as oxo group donors, whereas the $\mathrm{Mo}^{4+}$ cores act as oxo group acceptors, in a mechanism where the molybdenum intermediates the oxygen atom transfer from one substrate to the second substrate. This "double oxo transfer hypothesis", initially proposed to account for reactions with molybdenum model compounds [57-59], is supported by the chemical uniqueness of molybdenum [60]. The $\mathrm{Mo}^{6+, 5+, 4+}$ chemistry is dominated by the formation of oxides and sulfides, but the strong tendency of molybdenum to bind oxo groups is balanced by its ability to lose a single oxygen atom easily [60], making the molybdenum cores excellent "oxygen atom exchangers", provided that the thermodynamics of the reactions is favourable [61]. It is in the light of this molybdenum versatile chemistry that the reaction of oxygen abstraction from nitrite has to be thought.

The mechanism suggested does not dictate any obvious catalytic role for the molybdenum sulfhydryl group $\left(\mathrm{Mo}^{5+}-\mathrm{SH}\right.$ or $\left.\mathrm{Mo}^{4+}-\mathrm{SH}\right)$ in the nitrite reduction. However, 
its presence was shown to be crucial for the XO-catalysed nitrite reduction (Fig. 7). A similar phenomenon is observed in the XO inhibition by oxypurinol, where only the reduced sulfo-XO molecules are inhibited, in a process where the participation of the sulfhydryl group in the formation of the Mo-oxypurinol complex is not presently understood [40, 49, 50]. On the other hand, D. gigas AOR apparently does not need the sulfido group to catalyse the aldehyde oxidation [37] or the nitrite reduction. Understanding the role of the sulfido and oxo ligands during molybdenum reduction and oxidation is, thus, of prime importance in developing a deeper mechanistic insight into the XO- and AOR-mediated catalysis.

Physiological relevance of the XO- and AOR-catalysed nitrite reduction to $\mathrm{NO}$

In mammals, NO is involved in several physiological processes, such as vasodilatation and blood pressure regulation (through the well-known stimulation of guanylate cyclase), inhibition of platelet aggregation, neurotransmission, immune response, apoptosis, gene expression and as a mediator in a wide range of both antitumour and antimicrobial activities. Apart from those undoubtedly beneficial effects, it can not be forgotten that the overproduction of reactive nitrogen species (NO itself, but especially peroxynitrite) has been implicated in several pathophysiological conditions, including chronic inflammatory conditions, septic shock syndrome, diabetes and Parkinson's and Alzheimer's diseases. All of these reasons made the NO formation the focus of huge interest by the medical scientific community.

Under normoxia, NO is predominantly catalysed by NO synthases and its biological effects are accomplished by post-translational modification of transition metal centres and cysteine residues [62]. To control the specificity of NO signalling and to limit NO toxicity [63], NO synthase activity is tightly regulated and the NO lifetime is controlled through its rapid oxidation to nitrite and nitrate. In fact, nitrate and nitrite had long been regarded as merely inert end products of NO metabolism and of unfavourable dietary constituents. However, this "dogma" has been challenged by a growing number of independent studies showing that nitrite, under hypoxia and anoxia, can be reduced back to $\mathrm{NO}$, in vitro, in situ and in vivo, and can act as a vasodilator, as a modulator of mitochondrial respiration and as a cytoprotector during in vivo postischaemia injury in a wide range of tissues [31-35]. Nitrite present in blood and other tissues has thus been viewed as an NO storage form that could be made available under conditions of hypoxia and anoxia to ensure cell survival.

The pathways of nitrite reduction to NO, extensively reviewed recently [31-35], include non-enzymatic disproportionation at low $\mathrm{pH}$ values, reduction by deoxyhaemoglobin or myoglobin, by mitochondrial cytochromes and cytochrome $\mathrm{P}_{450}$, and through the enzymatic conversion by $\mathrm{XO}$ and aldehyde oxidase. The in vivo relative importance of each of those "nitrite-recycling" pathways is difficult to evaluate, because it is determined by multifactoral aspects: the molecular oxygen concentration, the cellular $\mathrm{pH}$ and redox state, and the tissue type (which determines the concentration of enzyme, nitrite and available reducing substrates). In the case of the XO-mediated pathway, besides the concentration of nitrite (the limiting substrate, given the millimolar $K_{\mathrm{m}}$ value and the micromolar physiological nitrite concentration), the molecular oxygen concentration present is particularly critical. Thus, at the end of the enzyme reductive half-reaction $\left(\mathrm{Mo}^{6+} \rightarrow \mathrm{Mo}^{4+}\right)$, the electrons introduced into the molybdenum site have two possible fates: (1) they could be transferred directly to nitrite (as depicted in Scheme 2) or (2) they could be intramolecularly distributed throughout the molybdenum, $\mathrm{Fe} / \mathrm{S}$ and flavin centres, according to the redox potentials of the centres. It should be noted that the reduction potentials of the $\mathrm{XO}$ centres are poised to favour the molybdenum oxidation and the flavin reduction (with the Fe/S acting as electrons "sinks"), and that the intramolecular electron transfer is much more rapid than any of the XO oxidation-reduction reactions [43]. So, if nitrite is to be reduced, the electrons must remain in the molybdenum centre. To accomplish that, a high concentration of the reducing substrate (to maintain the enzyme fully reduced) and a low concentration or absence of an additional oxidising substrate are crucial. The concentration of the oxidising substrate is particularly important in the case of molecular oxygen, because its reduction is much faster (with $k=35 \mathrm{~s}^{-1}$ for fully reduced enzyme [64]) than the reduction of nitrite. In fact, molecular oxygen was found to be a competitive inhibitor of the xanthine/XO-dependent NO formation and more than $90 \%$ inhibition is observed in aerobic conditions [25]. However, when NADH is the reducing substrate, the $\mathrm{XO}$-mediated $\mathrm{NO}$ formation is maintained at more than $70 \%$ of the anaerobic levels [25]. This phenomenon is probably due to the binding of NADH to the flavin, which blocks the access of the molecular oxygen. So, NADH would be the major reducing substrate for aerobic XO-catalysed NO formation; however, its high $K_{\mathrm{m}}(0.9 \mathrm{mM})$ and low $k_{\mathrm{cat}}\left(0.2 \mathrm{~s}^{-1}\right.$ [23]) values question its participation in the nitrite reduction. The cellular $\mathrm{pH}$ value would also have an important effect on the competition between nitrite and molecular oxygen, since low $\mathrm{pH}$ values (as observed during ischaemia, $\mathrm{pH}$ 5.5-6.5) would contribute to a faster nitrite reduction (data not shown and [23]).

In conclusion, the XO-mediated NO formation would depend on the competition between nitrite and molecular 
oxygen for the electrons provided by the reducing substrates. Under hypoxia and anoxia (2-20 $\mu \mathrm{M}$ and less than $2 \mu \mathrm{M}$ molecular oxygen, respectively), the resulting acidosis and the increased concentrations of xanthine and $\mathrm{NADH}$ will probably be sufficient to trigger the XO "nitrite-recycling" pathway. This prediction has actually been confirmed by several in situ studies performed with the XO-specific inhibitors allopurinol and oxypurinol [26$28,31,65]$. Under normoxic conditions, however, the XO pathway would be almost certainly abolished.

In bacteria, the NO production has been thought to occur only in the course of denitrification (reduction of nitrate to dinitrogen), and NO has been seen simply as an intermediate of the anaerobic "nitrate respiration". However, there is evidence that $\mathrm{NO}$ is involved in bacterial cell signalling and in cytoprotection against oxidative stress [66]. In addition, some bacterial and archaeal NO synthases, homologous to the oxygenase domain of the eukaryotic enzymes but lacking the reductase domain, were recently described [67]. These NO synthases successfully reduce arginine to NO, hijacking available cellular redox partners that are not normally committed to NO production to supply the required electrons. Together, those results show clearly that bacterial NO is not a "useless" by-product.

D. gigas AOR was first described by Moura et al. [68] and has been thought of as an aldehyde "scavenger", acting in a complex chain of electron-transfer proteins that links the oxidation of aldehydes to the reduction of protons [69]. The AOR-dependent nitrite reductase activity described herein could, therefore, constitute an alternative pathway to produce NO directly from aldehydes. As discussed above, the in vivo relative relevance of this "recycling" pathway would be determined by the competition between nitrite and the available physiological oxidising substrates. In AOR, Fe/S II is thought to be involved in the intramolecular electron transfer to an unknown physiological partner, probably flavodoxin [38], but not molecular oxygen. Besides the concentration of nitrite, which is again the limiting substrate (with an even higher $K_{\mathrm{m}}$ value of $4 \mathrm{mM}$ ), the cellular redox state would be of critical importance, since it controls the redox state of the protein partners of AOR.

\section{Conclusions}

The results described in the present work revealed a new catalytic performance for $\mathrm{AOR}$ - the nitrite reductase activity - and proposed a mechanism for the nitrite reduction catalysed by XO family enzymes. Given the XO and AOR known reactions (oxygen insertion into xanthine or aldehyde), the nitrite reduction (oxygen abstraction) described herein may be seen as an unexpected reaction. However, the molybdenum cores are well suited to promote the oxygen atom transfer. The reactions observed for purine catabolism (XO), aldehyde oxidation (AOR) and nitrite reduction (XO and $\mathrm{AOR}$ ) reflect different ways of atom transfer: insertion (i.e. aldehyde $\rightarrow$ carboxylic acid) and abstraction (nitrite $\rightarrow \mathrm{NO}$ ). In reality, these two types of oxygen transfer are similar reactions, where the molybdenum atom preferentially retains oxygen or promotes the oxygen release. Higher oxidation states of molybdenum seem to be involved in atom insertion, but lower oxidation states would favour atom abstraction (Scheme 2). So this activity is probably common to other members of the XO family. For this reason, we propose the existence of a new class of nitrite reductases, molybdenum-dependent, that could significantly amplify the biological capacity to produce NO.

Acknowledgments L.M. (SFRH/BPD/39036/2007) thanks Fundação para a Ciência e a Tecnologia, MCTES, for a fellowship grant. This work was supported by project PTDC/QUI-BIQ/100366/2008 financed by the Fundação para a Ciência e a Tecnologia, MCTES.

\section{References}

1. Hille R (2002) Trends Biochem Sci 27:360-367

2. Brondino CD, Rivas MG, Romão MJ, Moura JJG, Moura I (2006) Acc Chem Res 39:788-796

3. Schwarz G, Mendel RR, Ribbe MW (2009) Nature 460:839-847

4. Rivas MG, Carepo MS, Mota CS, Korbas M, Durand MC, Lopes AT, Brondino CD, Pereira AS, George GN, Dolla A, Moura JJ, Moura I (2009) Biochemistry 48:873-882

5. Bursakov SA, Gavel OY, Di Rocco G, Lampreia J, Calvete J, Pereira AS, Moura JJ, Moura I (2004) J Inorg Biochem 98:833-840

6. Hille R (1996) Chem Rev 96:2757-2816

7. Brondino CD, Romão MJ, Moura I, Moura JJ (2006) Curr Opin Chem Biol 10:109-114

8. Hille R (2005) Arch Biochem Biophys 433:107-116

9. Feng C, Tollin G, Enemark JH (2007) Biochim Biophys Acta 1774:527-539

10. Rothery RA, Workun GJ, Weiner JH (2008) Biochim Biophys Acta 1778:1897-1929

11. Roy R, Adams MW (2002) Met Ions Biol Syst 39:673-697

12. Hille R (2006) Eur J Inorg Chem 10:1913-1926

13. Enroth C, Eger BT, Okamoto K, Nishino T, Nishino T, Pai EF (2000) Proc Natl Acad Sci USA 97:10723-10728

14. Krenitsky TA, Neil SM, Elion GB, Hitchings GH (1972) Arch Biochem Biophys 150:585-599

15. Okamoto K, Matsumoto K, Hille R, Eger BT, Pai EF, Nishino T (2004) Proc Natl Acad Sci USA 101:7931-7936

16. Pauff JM, Zhang J, Bell CE, Hille R (2008) J Biol Chem 283:4818-4824

17. Dixon M, Thurlow S (1924) Biochem J 18:989-992

18. Fridovich I, Handler P (1957) J Biol Chem 228:67-76

19. Fridovich I, Handler P (1962) J Biol Chem 237:916-921

20. Millar TM, Stevens CR, Benjamin N, Eisenthal R, Harrison R, Blake DR (1998) FEBS Lett 427:225-228

21. Li H, Samouilov A, Liu X, Zweier JL (2003) Biochemistry 42:1150-1159 
22. Zhang Z, Naughton D, Winyard PG, Benjamin N, Blake DR, Symons MC (1998) Biochem Biophys Res Commun 249:767772

23. Li H, Samouilov A, Liu X, Zweier JL (2001) J Biol Chem 276:24482-24489

24. Godber HLJ, Doel JJ, Sapkota GP, Blake DR, Stevens CR, Eisenthal R, Harrison R (2000) J Biol Chem 275:7757-7763

25. Li H, Samouilov A, Liu X, Zweier JL (2004) J Biol Chem 279:16939-16946

26. Webb A, Bond R, McLean P, Uppal R, Benjamin N, Ahluwalia A (2004) Proc Natl Acad Sci USA 101:13683-13688

27. Baker JE, Sua J, Fua X, Hsub A, Gross GJ, Tweddell JS, Hogg N (2007) J Mol Cell Cardiol 43:437-444

28. Li H, Cui H, Kundu TK, Alzawahra W, Zweier JL (2008) J Biol Chem 283:17855-17863

29. Garattini E, Fratelli M, Terao M (2008) Cell Mol Life Sci 65:1019-1048

30. Li H, Kundu TK, Zweier JL (2009) J Biol Chem 284:33850-33858

31. Lundberg JO, Weitzberg E (2005) Arterioscler Thromb Vasc Biol 25:915-922

32. Lundberg JO, Weitzberg E (2009) Arch Pharm Res 32:1119-1126

33. Faassen EE, Bahrami S, Feelisch M, Hogg N, Kelm M, KimShapiro DB, Kozlov AV, Li H, Lundberg JO, Mason R, Nohl H, Rassaf T, Samouilov A, Slama-Schwok A, Shiva S, Vanin AF, Weitzberg E, Zweier JL, Gladwin MT (2009) Med Res Rev 29:683-741

34. Lundberg JO, Gladwin MT, Ahluwalia A, Benjamin N, Bryan NS, Butler A, Cabrales P, Fago A, Feelisch M, Ford PC, Freeman BA, Frenneaux M, Friedman J, Kelm M, Kevil CG, Kim-Shapiro DB, Kozlov AV, Lancaster JR, Lefer DJ, McColl K, McCurry K, Patel RP, Petersson J, Rassaf T, Reutov VP, Richter-Addo GB, Schechter A, Shiva S, Tsuchiya K, Faassen EE, Webb AJ, Zuckerbraun BS, Zweier JL, Weitzberg E (2009) Nat Chem Biol 5:865-869

35. Zweier JL, Li H, Samouilov A, Liu X (2010) Nitric Oxide 22:83-90

36. Rebelo JM, Dias JM, Huber R, Moura JJ, Romão MJ (2001) J Biol Inorg Chem 6:791-800

37. Santos-Silva T, Ferroni F, Thapper A, Marangon J, González PJ, Rizzi AC, Moura I, Moura JJ, Romão MJ, Brondino CD (2009) J Am Chem Soc 131:7990-7998

38. Krippahl L, Palma N, Moura I, Moura JJG (2006) Eur J Inorg Chem 19:3835-3840

39. Turner N, Barata B, Bray RC, Deistung J, Le Gall J, Moura JJ (1987) Biochem J 243:755-761

40. Massey V, Komai H, Palmer G, Elion GB (1970) J Biol Chem 245:2837-2844

41. Cornish-Bowden A (1995) Fundamentals of enzyme kinetics. Portland Press, London
42. Xia Y, Zweier JL (1997) Proc Natl Acad Sci USA 94:12705-12710

43. Olson JS, Ballou DP, Palmer G, Massey V (1974) J Biol Chem 249:4363-4382

44. Hunt J, Massey V (1994) J Biol Chem 269:18904-18914

45. McDonald CC, Phillips WD, Mower HF (1965) J Am Chem Soc 87:3319-3326

46. Woolum JC, Tiezzi E, Commoner B (1968) Biochim Biophys Acta 160:311-320

47. Massey V, Edmondson D (1970) J Biol Chem 245:6595-6598

48. Coughlan MP, Johnson JL, Rajagopalan KV (1980) J Biol Chem 255:2694-2699

49. Hawkes TR, George G, Bray RC (1984) Biochem J 218:961-968

50. Okamoto K, Egerb BT, Nishino T, Pai EF, Nishino T (2008) Nucleosides Nucleotides Nucleic Acids 27:888-893

51. Maia L, Duarte RO, Ponces-Freire A, Moura JJG, Mira L (2007) J Biol Inorg Chem 12:777-787

52. Lowe DJ, Barber MJ, Pawlik RT, Bray RC (1976) Biochem J 155:81-85

53. Howes BD, Pinhal NM, Turner NA, Bray RC, Anger G, Ehrenberg A, Raynor JB, Lowe DJ (1990) Biochemistry 29:6120-6127

54. Gautier C, Faassen E, Mikula I, Martasek P, Slama-Schwok A (2006) Biochem Biophys Res Commun 341:816-821

55. Stiefel EI (1973) Proc Nat Acad Sci USA 70:988-992

56. Rajapakshe A, Snyder RA, Astashkin AV, Bernardson P, Evans DJ, Young CG, Evans DH, Enemark JH (2009) Inorg Chim Acta 362:4603-4608

57. Holm RH (1987) Chem Rev 87:1401-1449

58. Holm RH, Kennepohl P, Solomon EI (1996) Chem Rev 96:2239-2314

59. Schultz BE, Hille R, Holm RH (1995) J Am Chem Soc 117:827-828

60. Burgrnayer SJN, Stlefel EI (1985) J Chem Educ 62:943-953

61. Harlan EE, Berg JM, Holm RH (1986) J Am Chem Soc 108:6992-7000

62. Stamler JS, Lamas S, Fang FC (2001) Cell 106:675-683

63. Kone BC, Kuncewicz T, Zhang W, Yu ZY (2003) Am J Physiol Ren Physiol 285:178-190

64. Hille R, Massey V (1981) J Biol Chem 256:9090-9095

65. Duranski MR, Greer JJ, Dejam A, Jaganmohan S, Hogg N, Langston W (2005) J Clin Invest 115:1232-1240

66. Gusarov I, Nudler E (2005) Proc Natl Acad Sci USA 102:13855-13860

67. Gusarov I, Starodubtseva M, Wang Z, McQuade L, Lippard SJ, Stuehr DJ, Nudler E (2008) J Biol Chem 283:13140-13147

68. Moura JJG, Xavier AV, Bruschi M, Le Gall J, Hall DO, Cammack R (1976) Biochem Biophys Res Commun 72:782-789

69. Barata BA, LeGall J, Moura JJ (1993) Biochemistry 32:11559-11568 